Supporting information for:

\title{
Synthesis of $\eta^{4}: \pi^{2}$-Exocyclic-Diene Iridium(I) Complexes Derived from 1,3-Oxazolidin-2-ones and their Transformation into Iridium(III) Derivatives by Reaction with a Phosphine and with Aldehydes
}

\author{
Verónica Salazar, ${ }^{* \dagger}$ Oscar R. Suárez-Castillo, ${ }^{\dagger}$ Rosa Padilla, ${ }^{\dagger}$ J. Carlos Macías P, ${ }^{\dagger}$ Miguel \\ Ángel Méndez-Rojas, ${ }^{\dagger, \grave{j}}$ Joaquín Tamariz, ${ }^{\S}$ and Adriana Benavides ${ }^{\S}$. \\ Centro de Investigaciones Químicas, Universidad Autónoma del Estado de Hidalgo, \\ Ciudad Universitaria, Km. 4.5 Carretera Pachuca-Tulancingo, Pachuca Hgo., México, and \\ Departamento de Química Orgánica, Escuela Nacional de Ciencias Biológicas, IPN, Prol. \\ Carpio y Plan de Ayala, 11340 México, D.F.
}

\section{TABLE OF CONTENTS:}

Figure S1.

A) ${ }^{1} \mathrm{H}$ NMR spectrum $\left(\mathrm{CDCl}_{3}\right)$ of the crude material obtained in the reaction that yields compound 4a. The signals with an asterisk correspond to free aldehyde (the reation is carried out with en excess of this reagent. Two more signals for this molecule are located at a field lower than displayed).

B) ${ }^{1} \mathrm{H}$ NMR spectrum $\left(\mathrm{CDCl}_{3}\right)$ of isolated $\mathbf{4 a}$.

Set of figures S2.

These drawings contain ${ }^{1} \mathrm{H},{ }^{13} \mathrm{C}\left\{{ }^{1} \mathrm{H}\right\}$, HMBC and HMQC for compounds 1-4. 

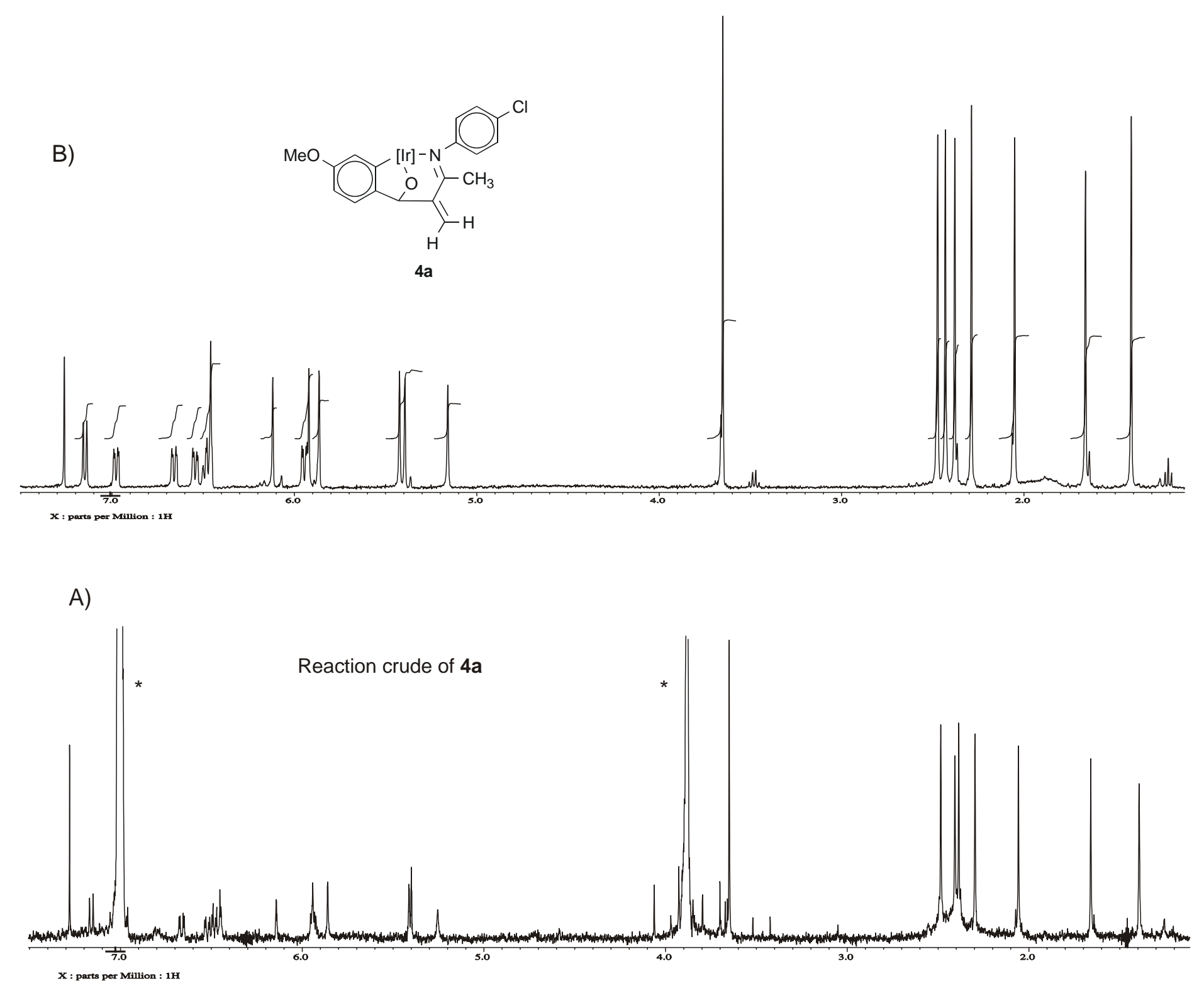


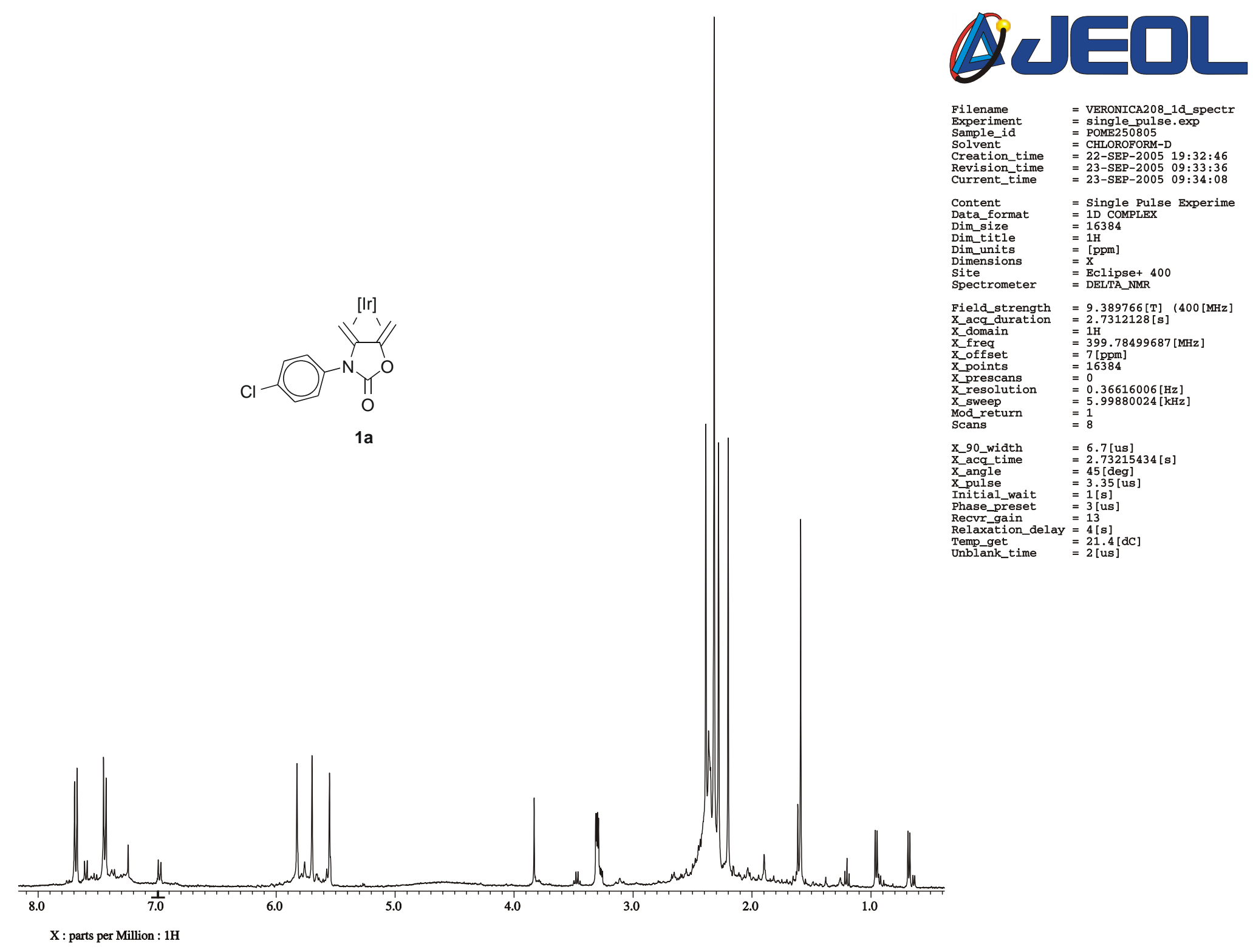




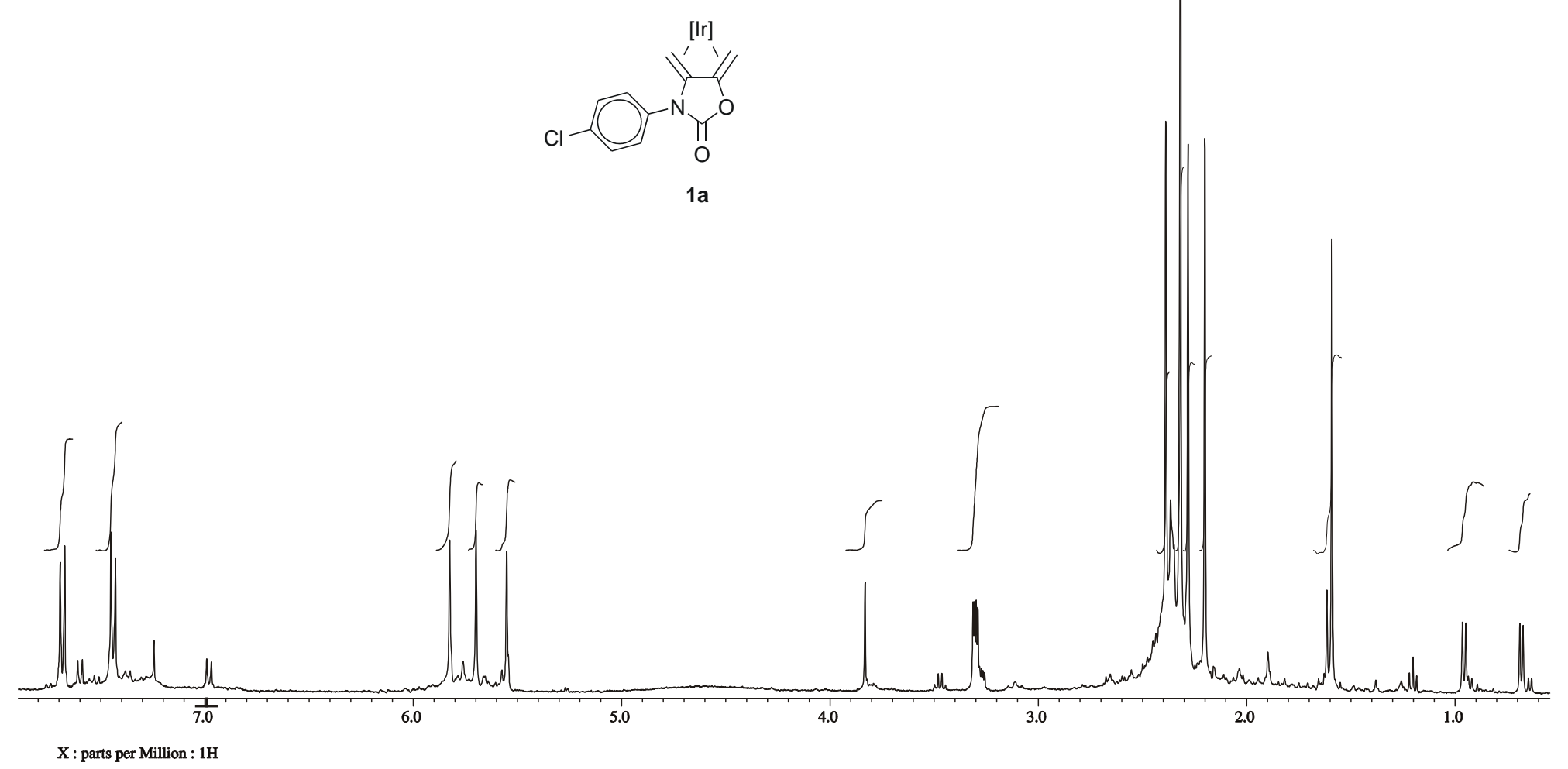




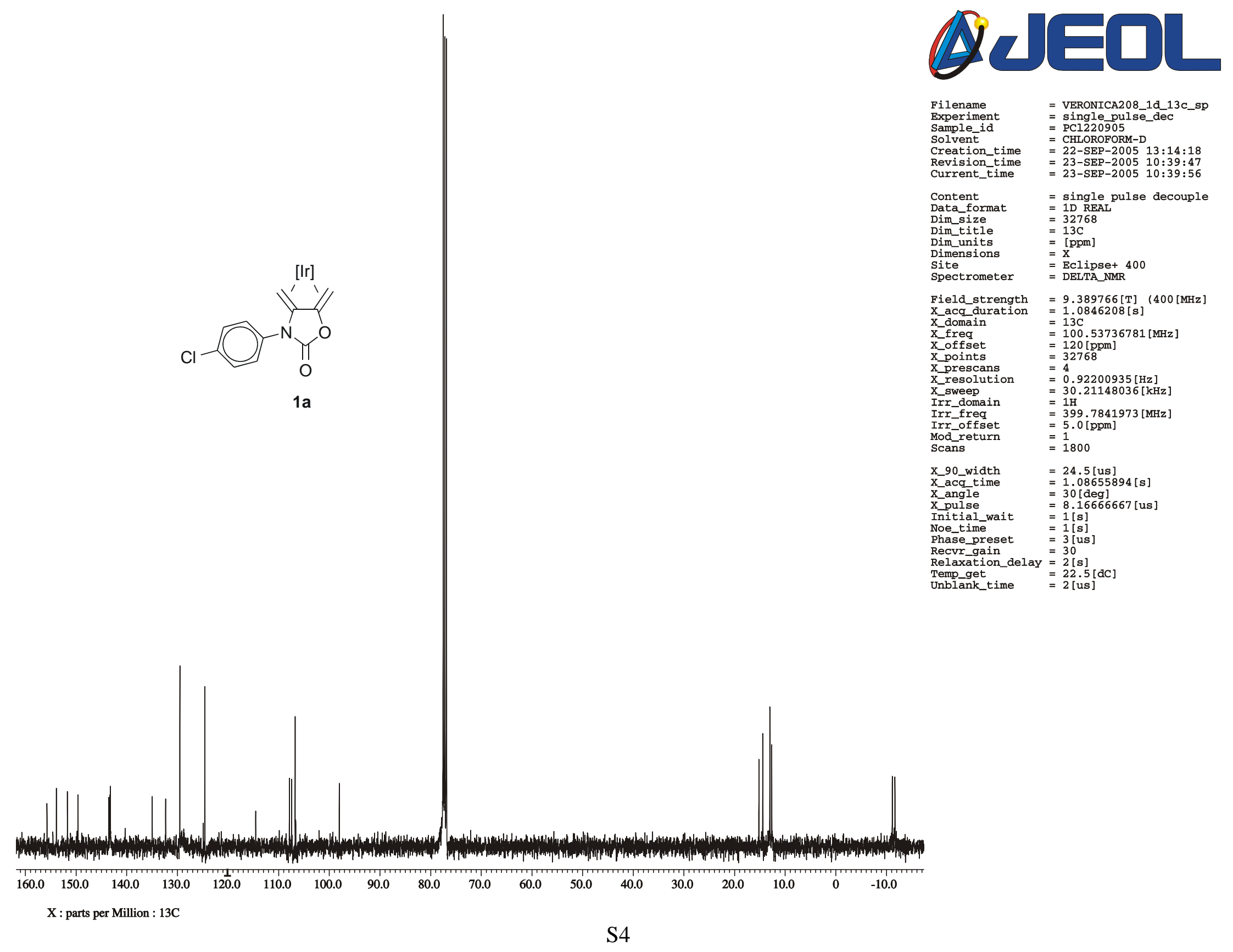




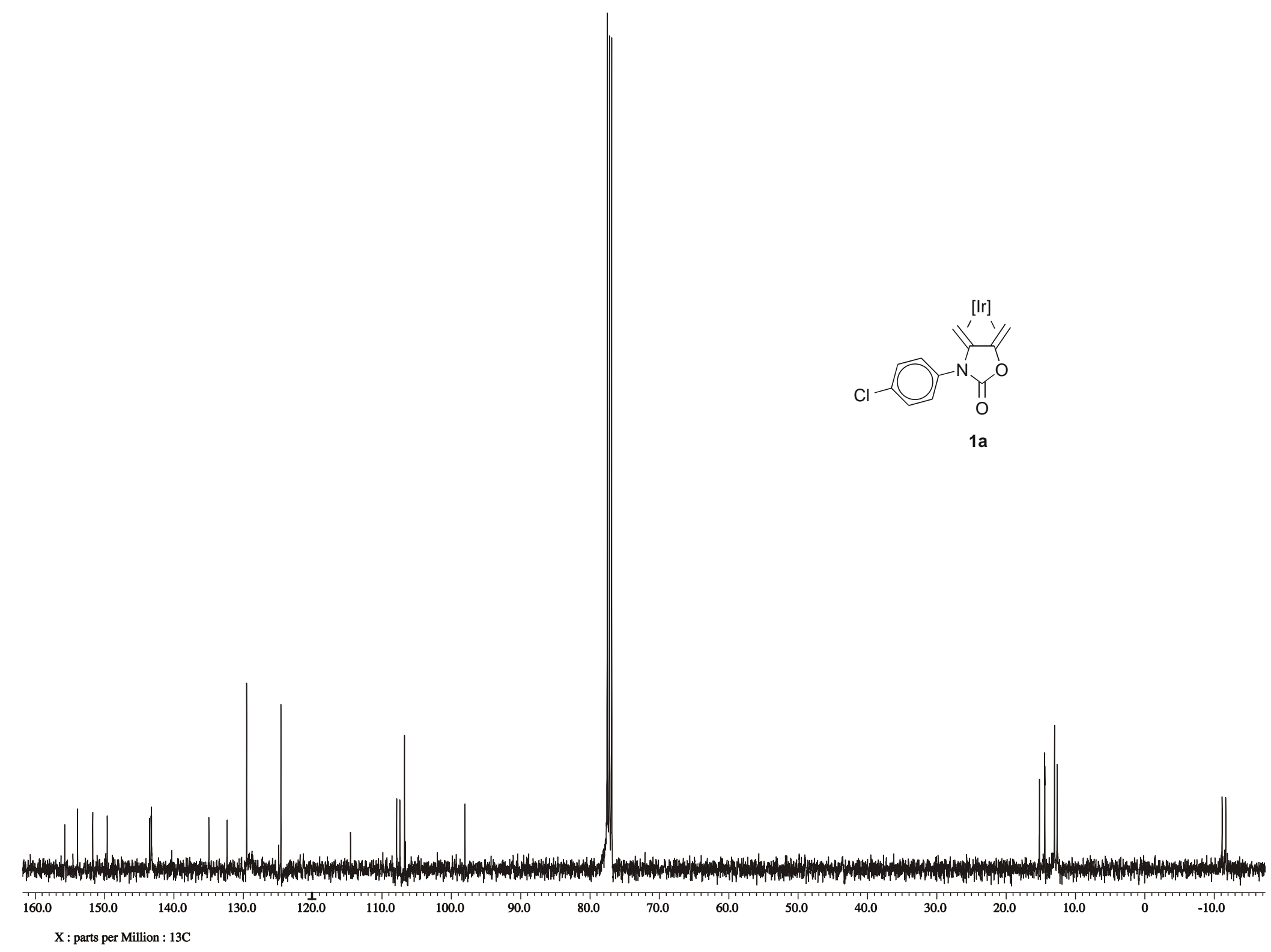




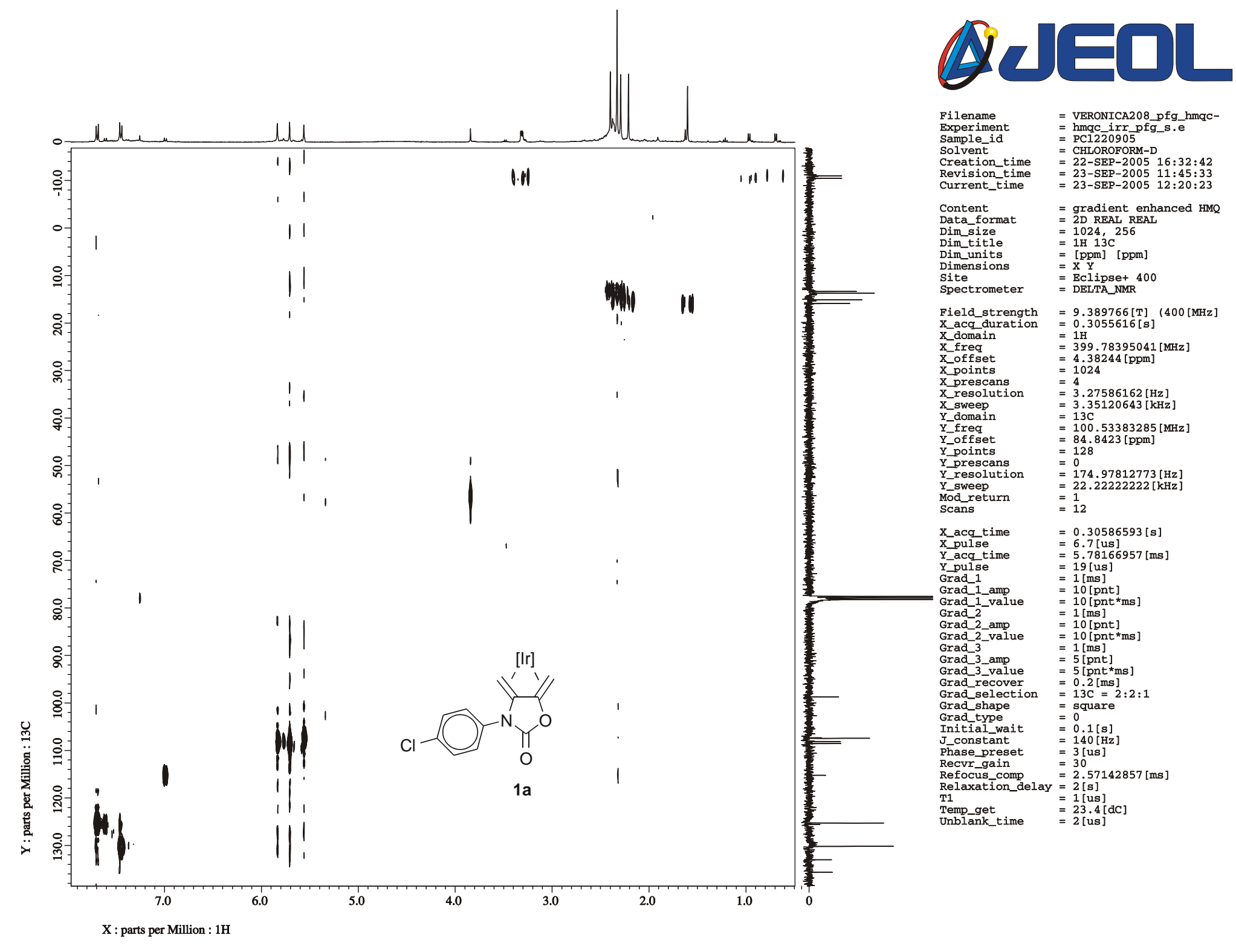




$$
[B
$$




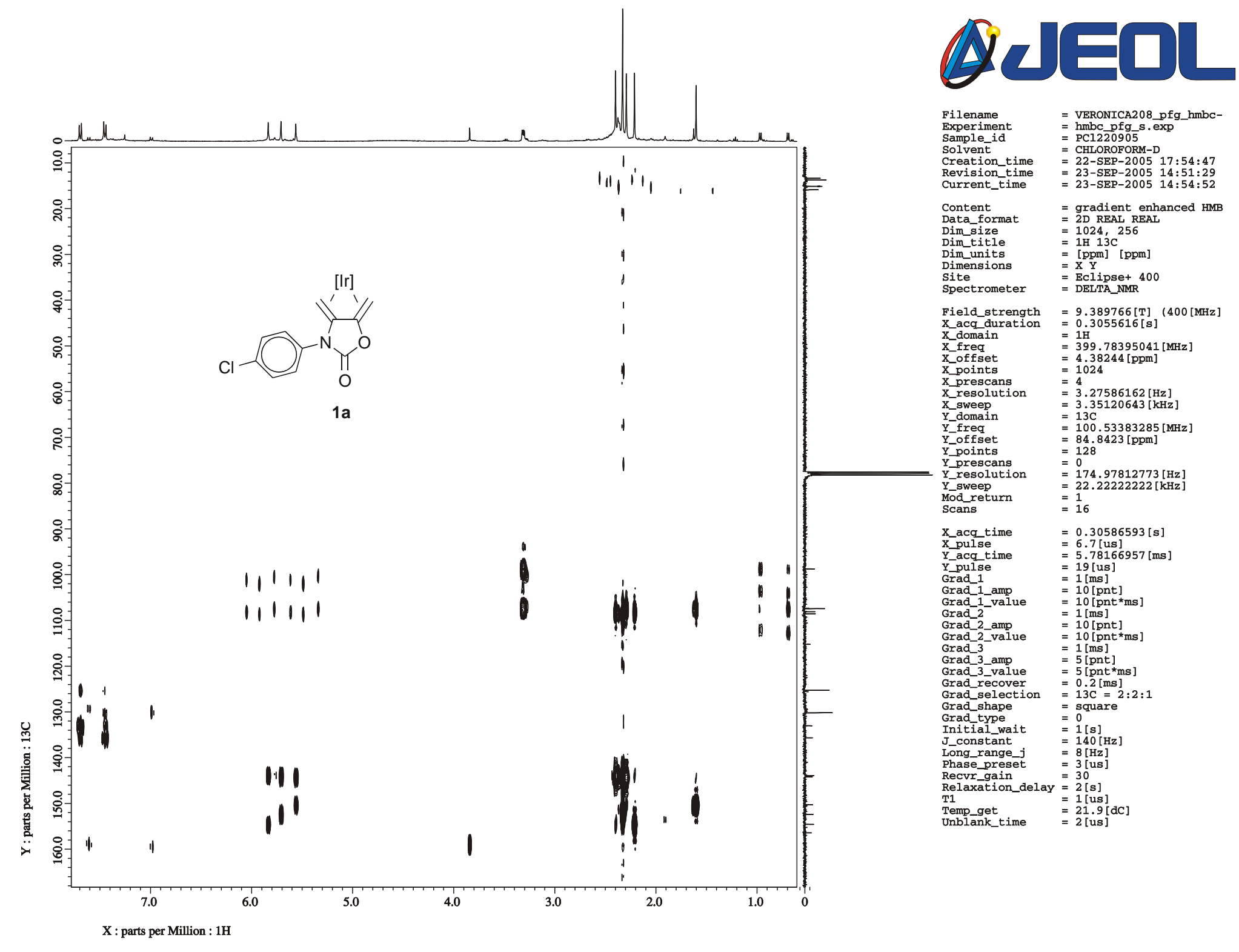




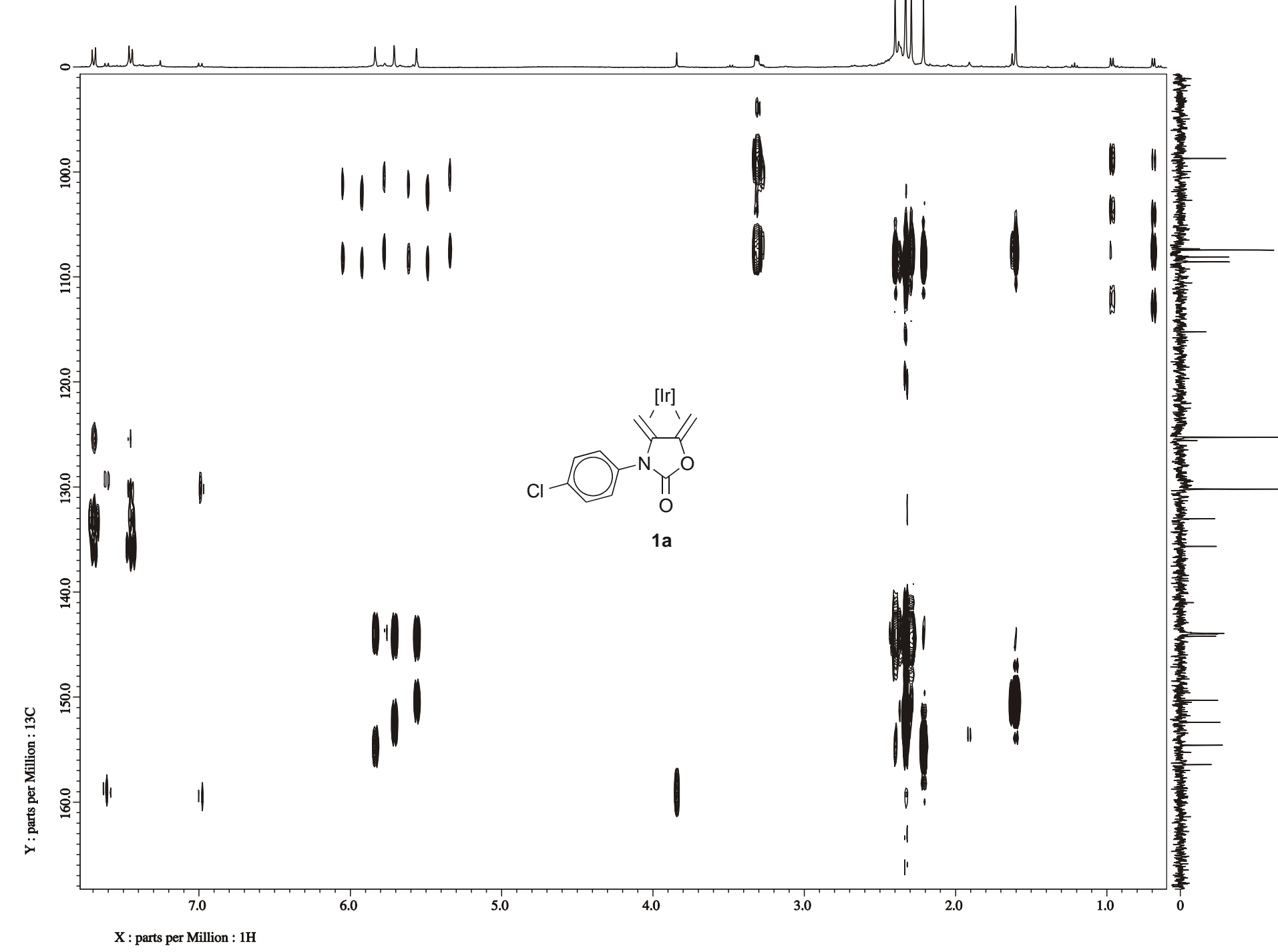




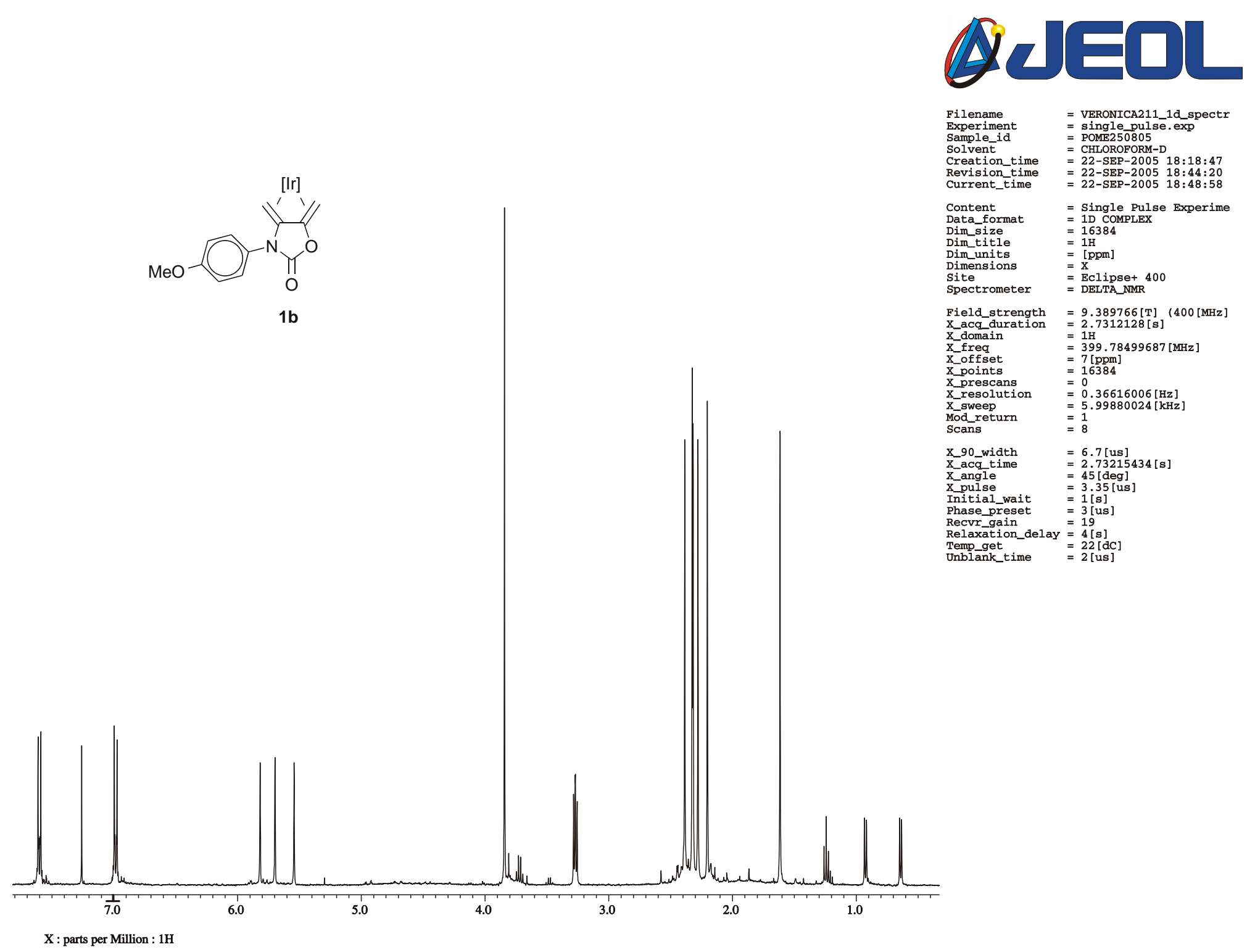




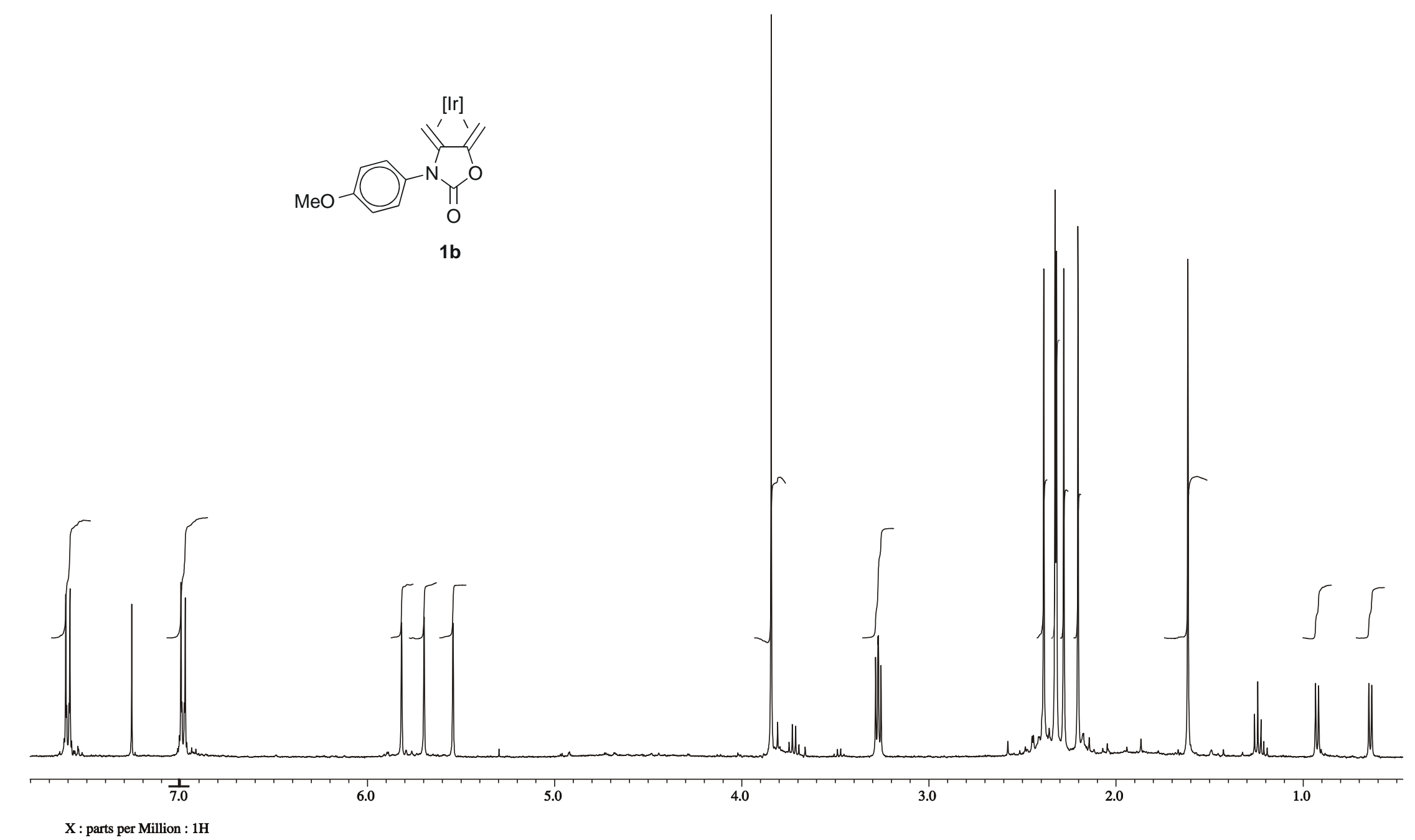




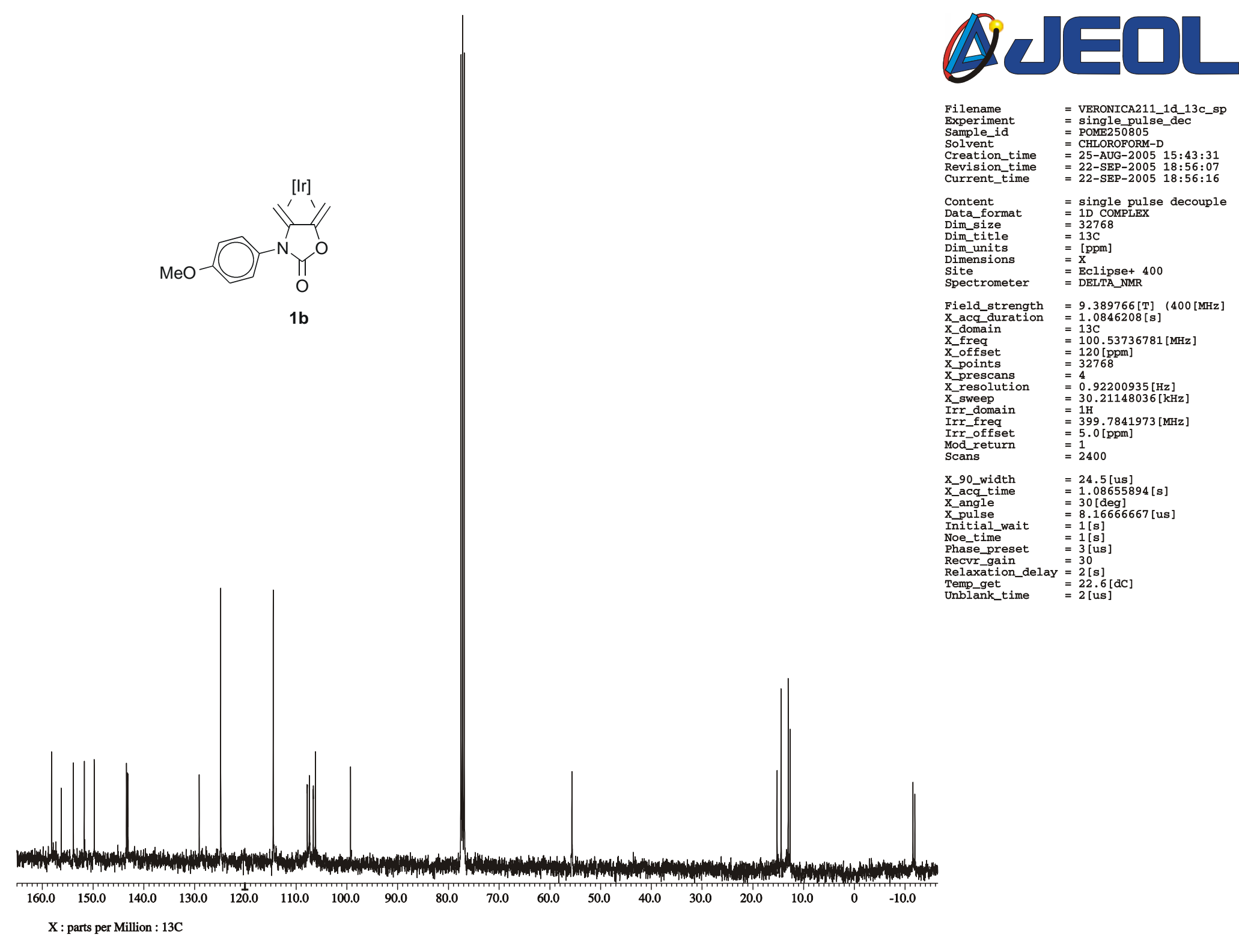




$$
1
$$




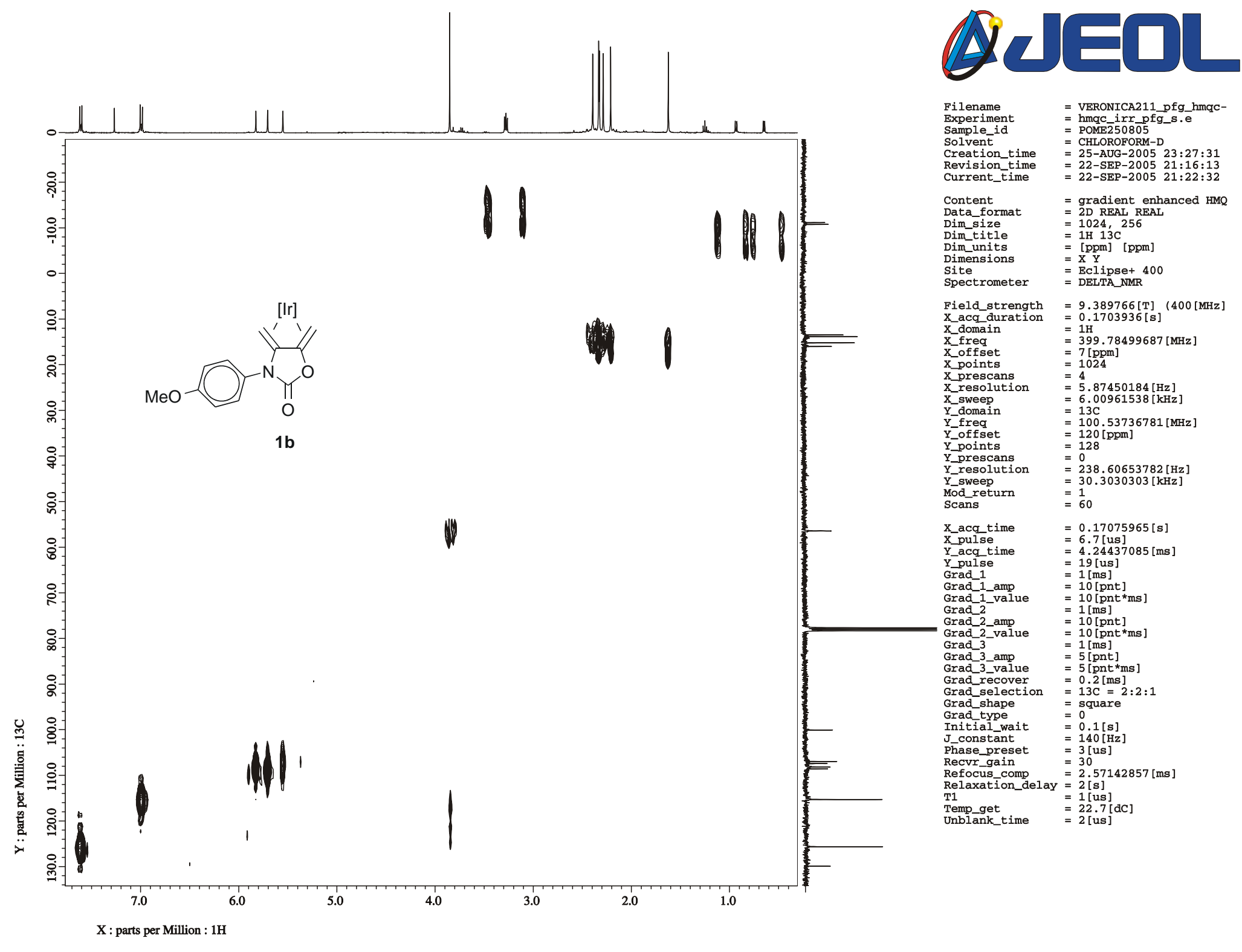




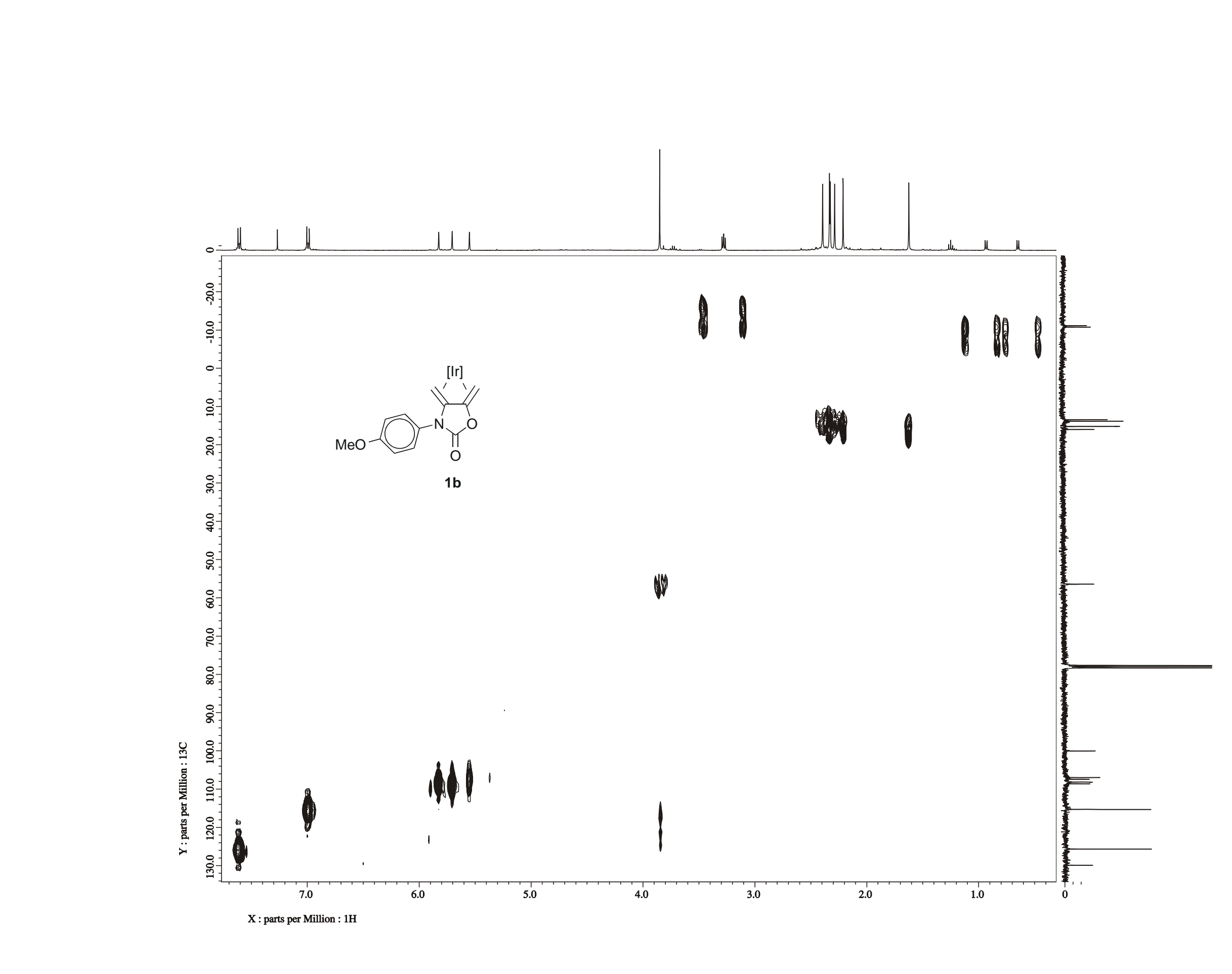




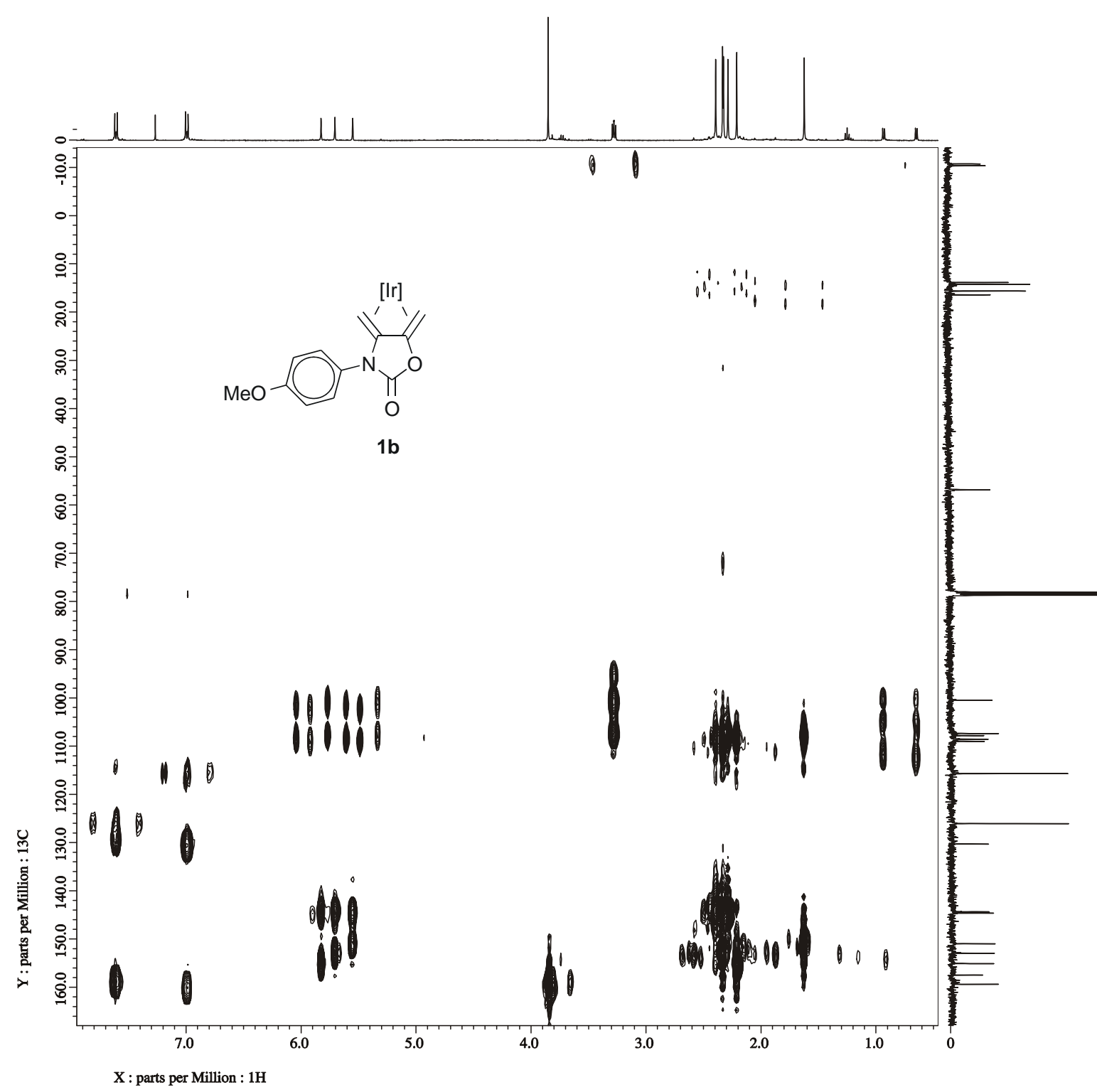

\section{Q UEOL}

$\begin{array}{ll}\text { Filename } & =\text { VERONICA211_pfg_hmbc- } \\ \text { Experiment } & =\text { hmbc_pfg_s.exp }\end{array}$

Sample_id $=$ POME250805

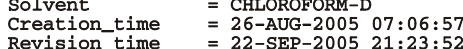

current_time $\quad=22$-SEP-2005 21:26:14

Content $=$ gradient enhanced HMB

Dim_size $=1024,256$

Dim_units $=$ [ppm] [ppm]

$\begin{array}{ll}\text { Dimensions } & =\mathrm{XY} \\ \text { Site } & =\text { Eclipse+ } 400\end{array}$

$\begin{array}{ll}\text { Spectrometer } & =\text { EClipse+ } \\ \text { S DELTA_NMR }\end{array}$

$\begin{aligned} \text { Field_strength } & =9.389766[\mathrm{~T}] \quad(400[\mathrm{MHz}]\end{aligned}$

$\begin{array}{ll}\text { X-domain } & =1 \mathrm{H} \\ \text { X_freq } & =399.78499687[\mathrm{MHz}\end{array}$

$\begin{array}{ll} & =7[\mathrm{ppm}] \\ \mathrm{X} \text { _offiset } & =1024\end{array}$

$\begin{array}{ll} & =4 \\ X \text { _rescons } & \\ X & =5.87450184[\mathrm{~Hz}]\end{array}$

X_sweep

$\begin{array}{ll}\text { freq } & =100.53736781[\mathrm{MHz}] \\ \text { offset } & =120[\mathrm{ppm}]\end{array}$

point $=128$

$\begin{array}{ll}\text { prescans } & =0 \\ \text { resolution } & =238.60653782[\mathrm{~Hz}]\end{array}$

Y_sweep

$\underset{\text { Scans }}{\text { Mod_return }}=$

$\begin{array}{ll}\text { X_acq_time } & =0.17075965[\mathrm{~s}] \\ \mathrm{X} \text { pulse } & =6.7[\mathrm{us}]\end{array}$

$\begin{array}{ll} & =0.7 \text { [us] } \\ \text { Yaca time } & =4.24437085[\mathrm{~ms}]\end{array}$

$\begin{array}{ll}\text { Y_pulse } & =19 \text { [us] } \\ \text { Grad_1 } & =1 \text { [ms] }\end{array}$

$\begin{array}{ll}\text { Grad_1_amp } & =10[\mathrm{pnt}] \\ \mathrm{Grad}_{-} 1 \text {-value } & =10\left[\mathrm{pnt}{ }^{*} \mathrm{~ms}\right]\end{array}$

$\begin{array}{ll}\text { Grad_2 } & =1[\mathrm{~ms}] \\ \text { Grad_2_amp } & =10 \text { [pnt] } \\ \text { Grad_2_value } & =10 \text { [pnt*ms] }\end{array}$

Grad-3 $=1$ [ms]

Grad-3_value $=5$ [nont $x_{\mathrm{m}}$

$\begin{array}{ll}\text { Grad_selection } & =0.2[\mathrm{~ms}] \\ & =13 \mathrm{C}=2: 2: 1\end{array}$

Grad-shape

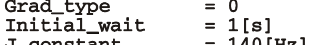

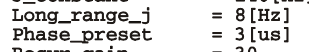

Relaxation_delay $=2[s]$

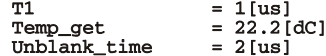




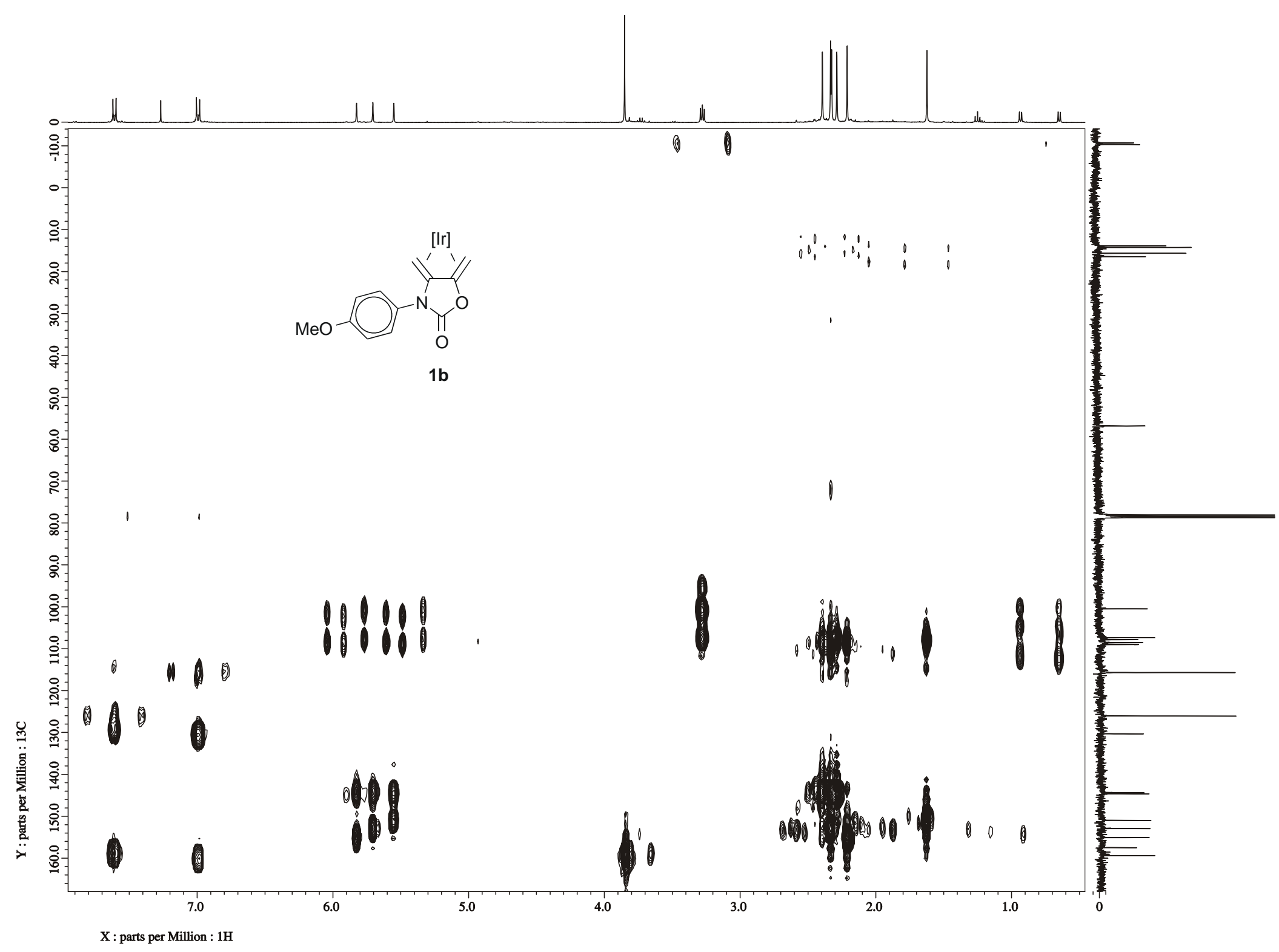




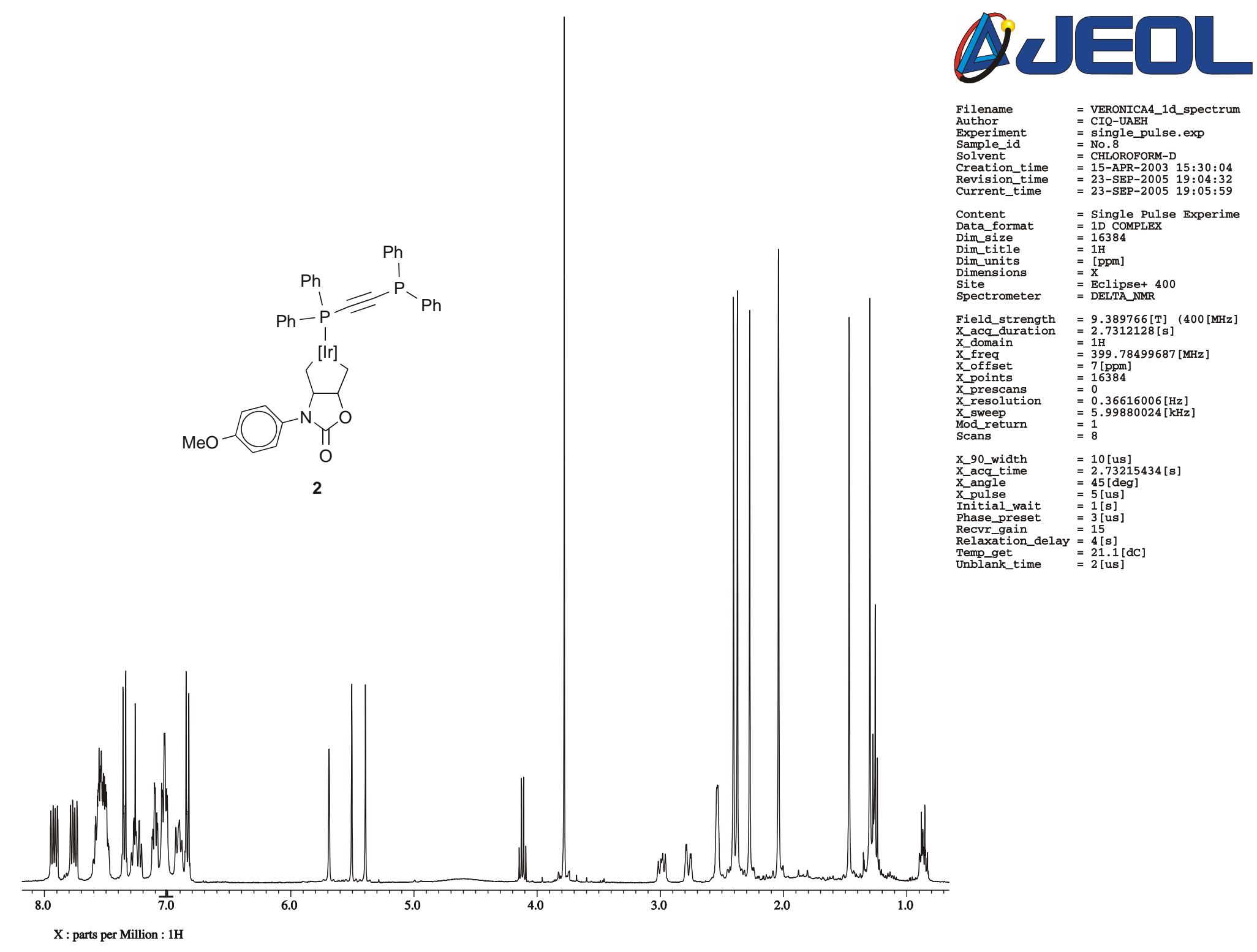




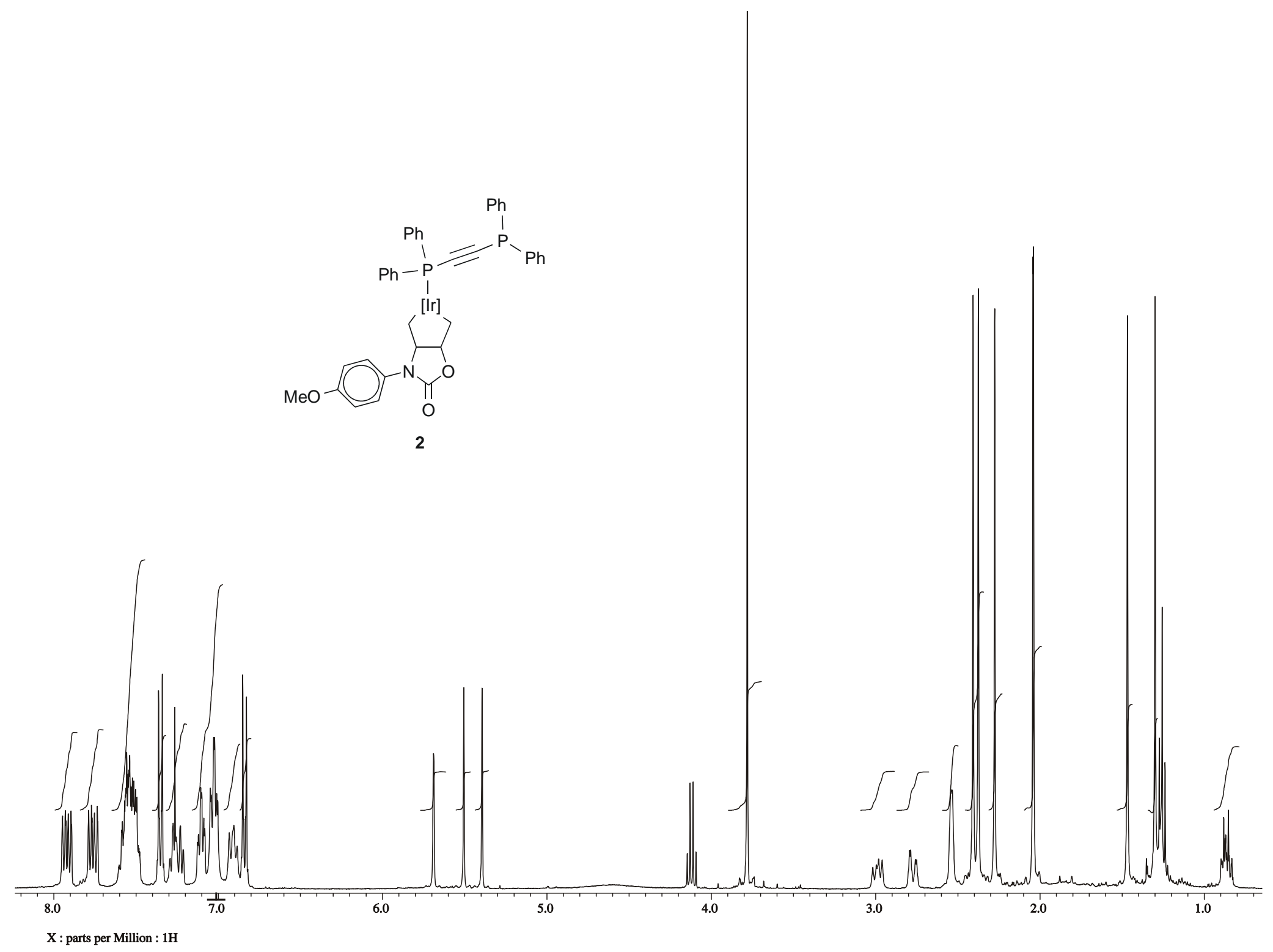




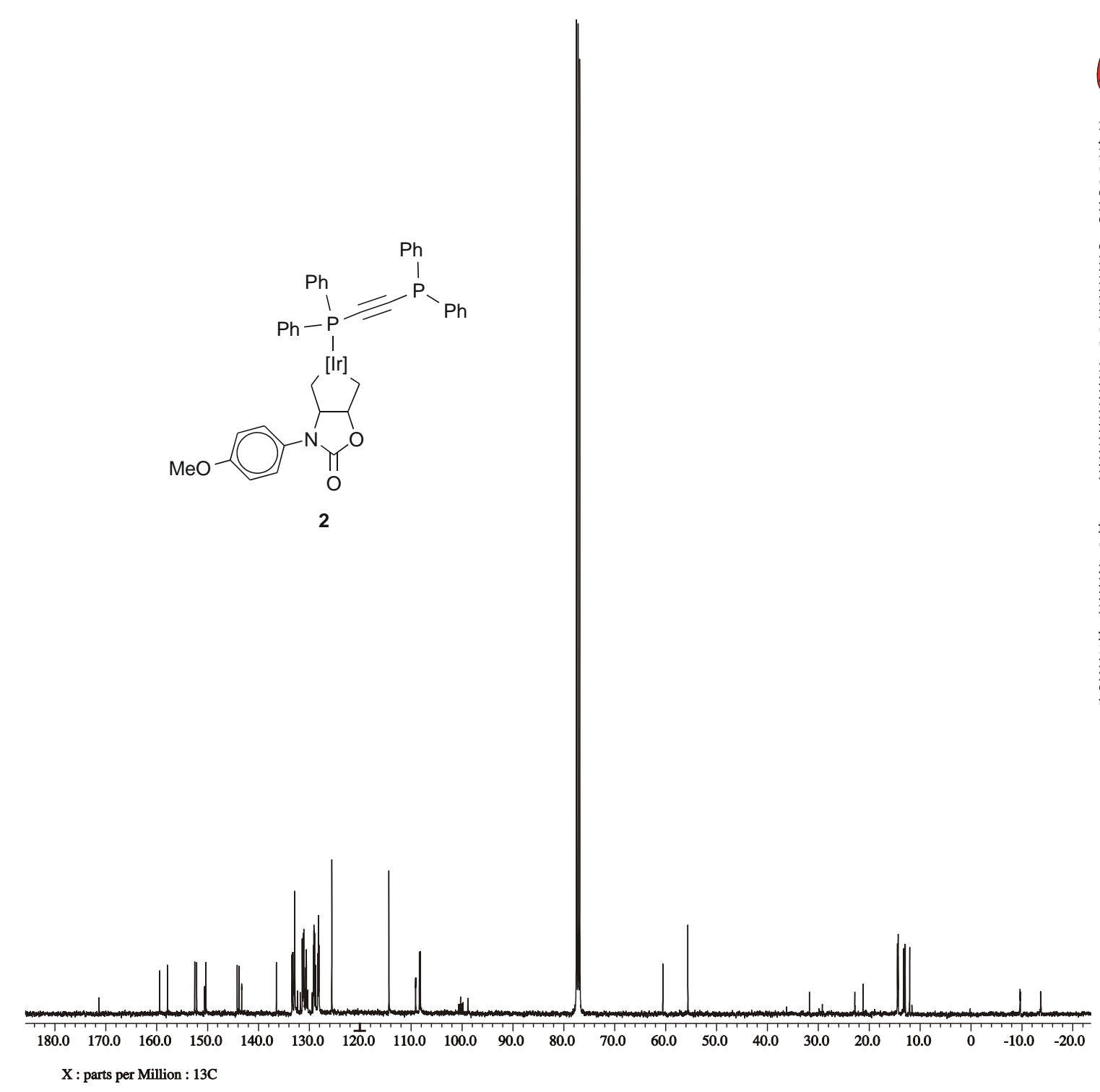

\section{QUEOL}

Filename = VERONICA4_1d_13c_spec

Experiment $\quad=$ single_pulse_dec

Solvent $=$ CHLOROFORM-D

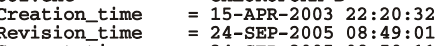

$\begin{array}{ll}\text { Content } & =\text { single pulse decouple } \\ \text { Data_format } & =1 \mathrm{D} \text { compLEX }\end{array}$

Dim_size

$\begin{aligned} & =32768 \\ & =13 \mathrm{C}\end{aligned}$

imensions

$\begin{array}{ll} & =\text { Eclipse+ } 400 \\ \text { Spectrometer } & =\text { DELTA NMR }\end{array}$

Field_strength $=9.389766[\mathrm{TT}](400[\mathrm{MHz})$ $\begin{array}{ll}\text { X_acq_duration } & =1.0846208[\mathrm{~s}] \\ \text { X_domain } & =13 \mathrm{C} \\ \text { X_freq } & =100.53736781[\mathrm{MHz}]\end{array}$

_points

$=0.92200935[\mathrm{~Hz}]$
$=30.21148036[\mathrm{kHz}]$

Irr_freq

$=399.7841973[\mathrm{MHz}]$
$=5.0[\mathrm{ppm}]$

$=1$

$\begin{array}{ll}\text { X_90_width } & =10.7 \text { [us] } \\ \text { X } & =1.08655894[\mathrm{~s}]\end{array}$

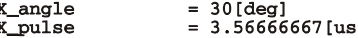

Initial_w

Noe_time

$=1$ is

$\begin{aligned} & =1 \\ & =30 \\ & =2[\mathrm{~s}]\end{aligned}$

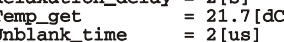

$\mathrm{X}$ : parts per Million : $13 \mathrm{C}$ 


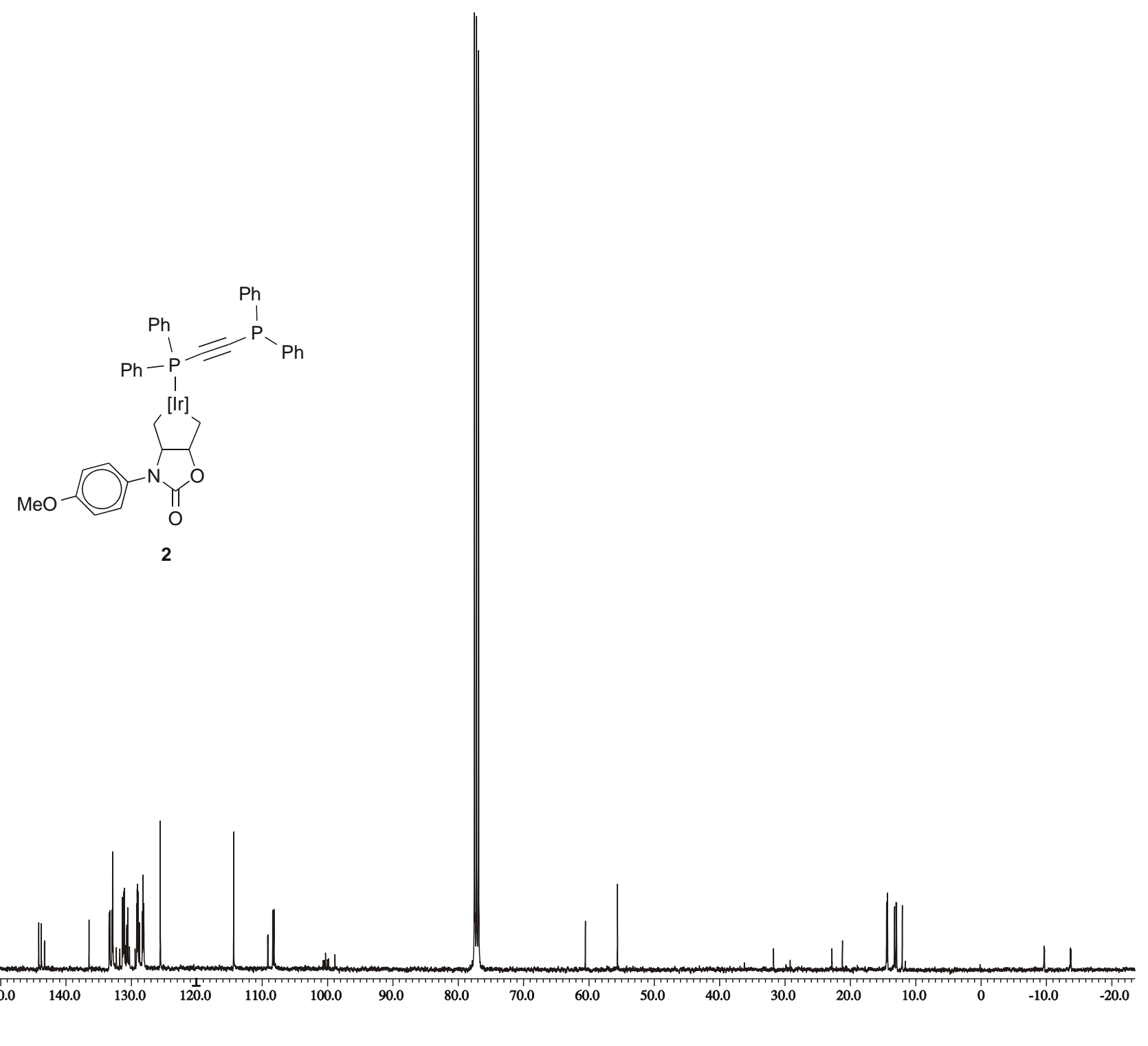




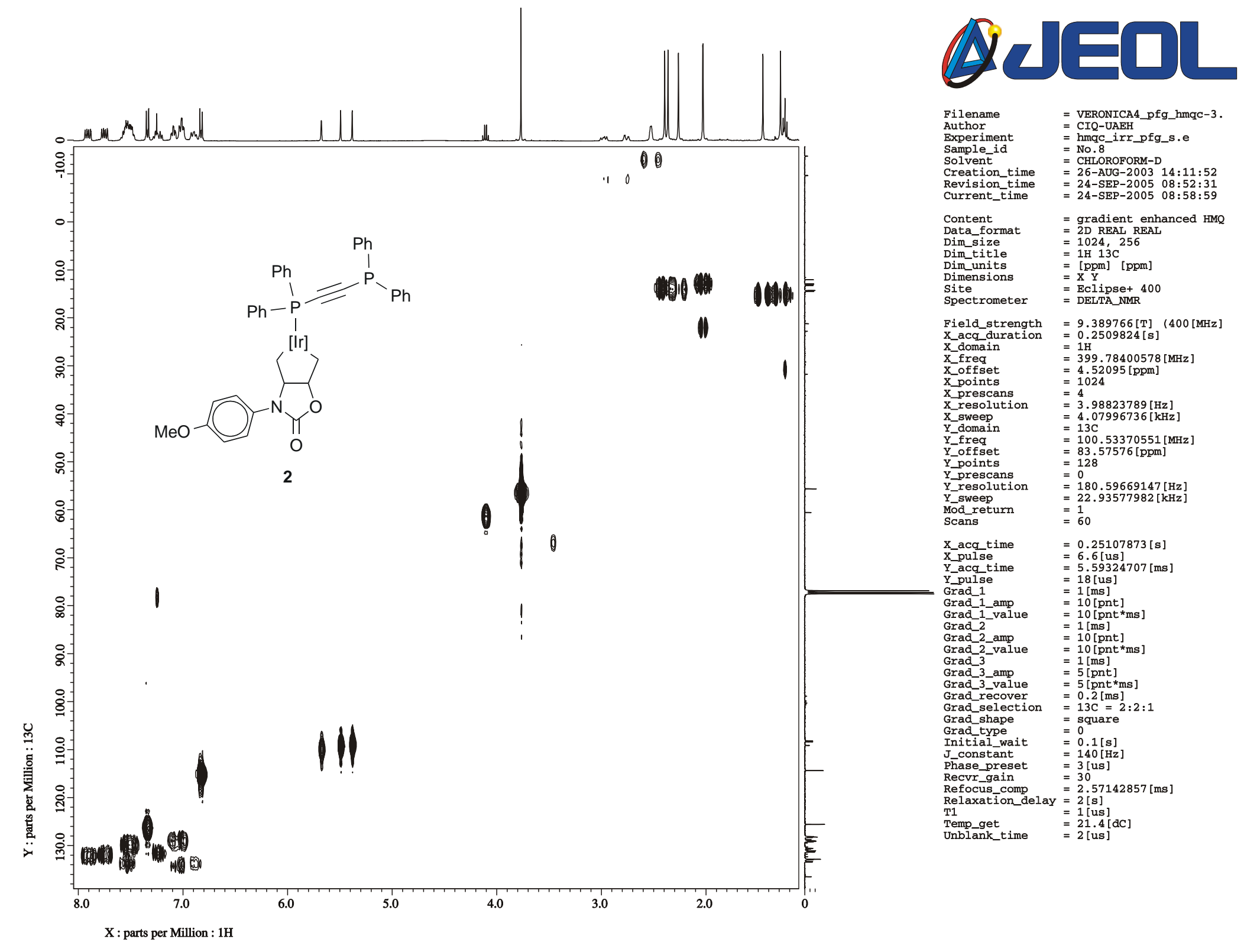




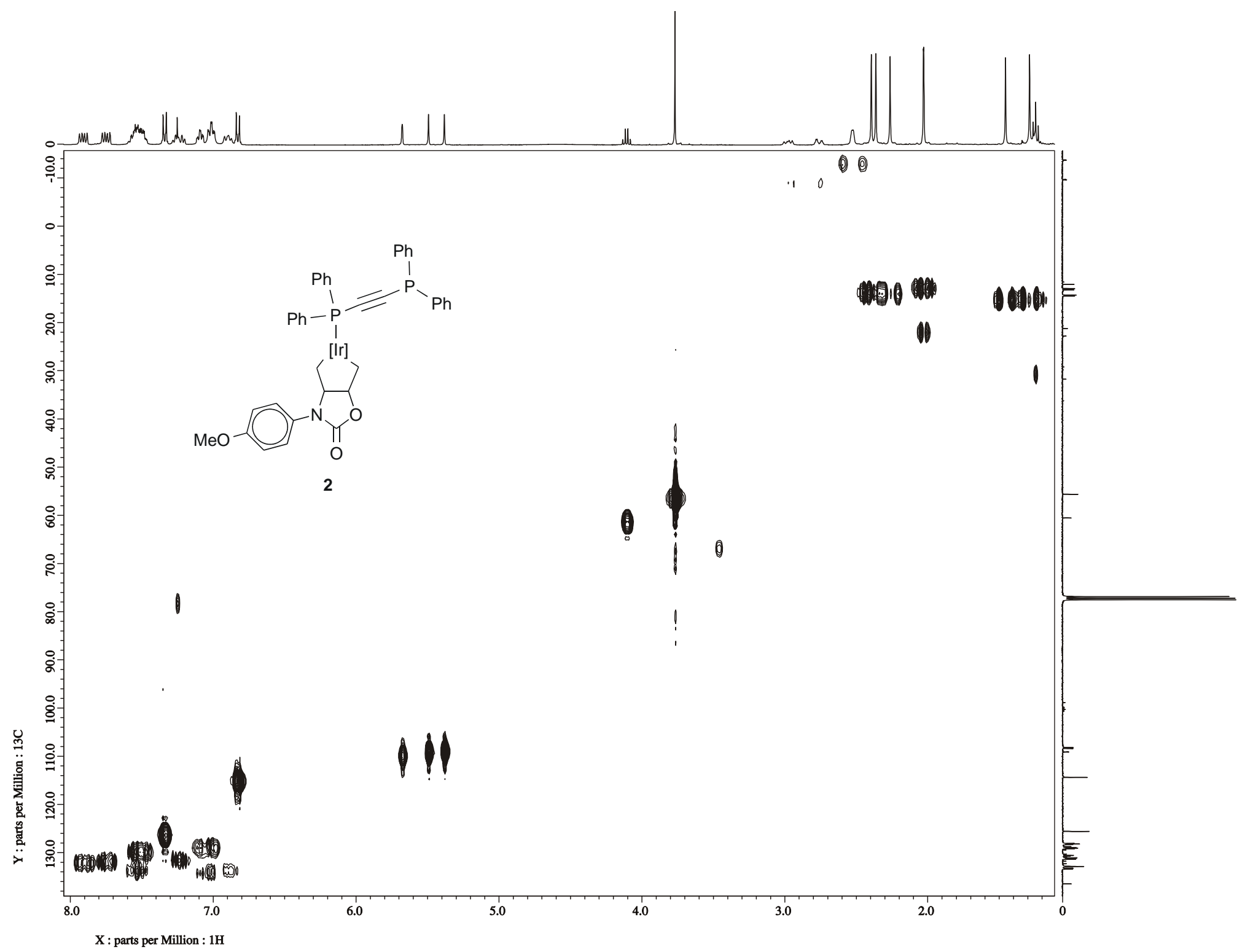




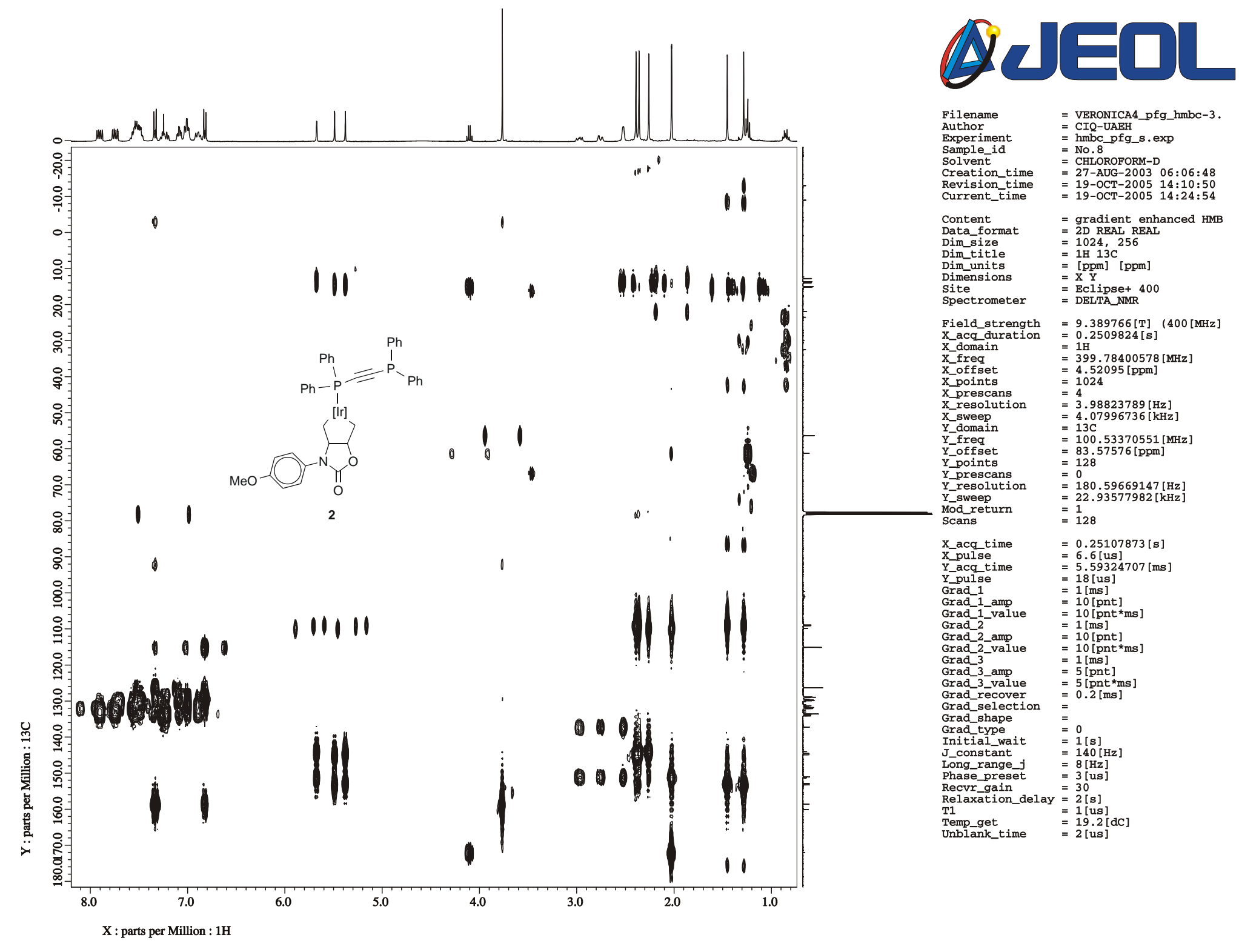




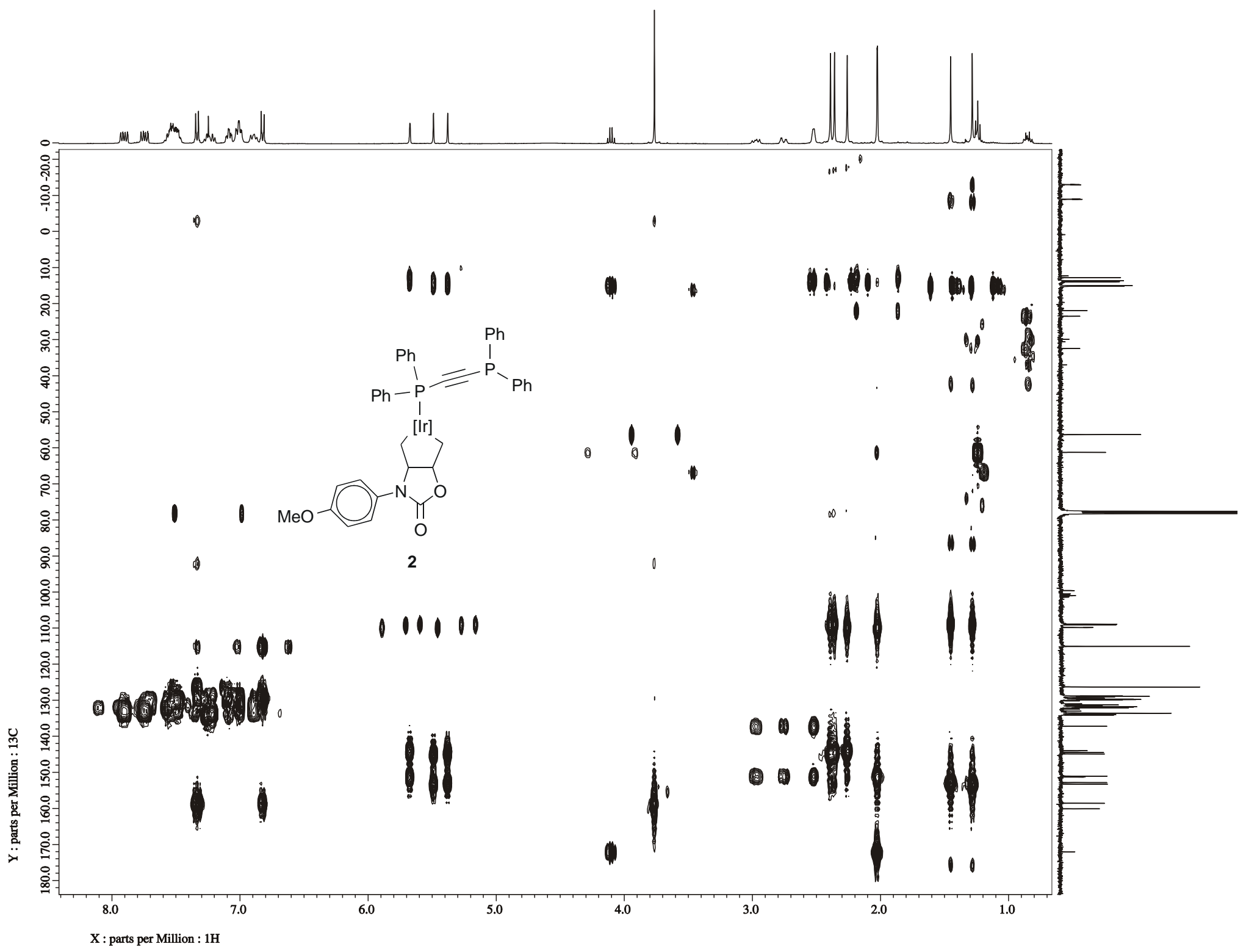

S25 


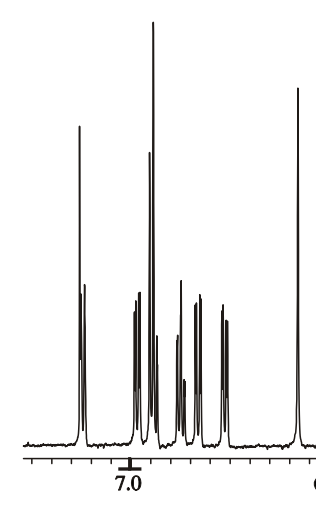

$X$ : parts per Million : $1 \mathrm{H}$
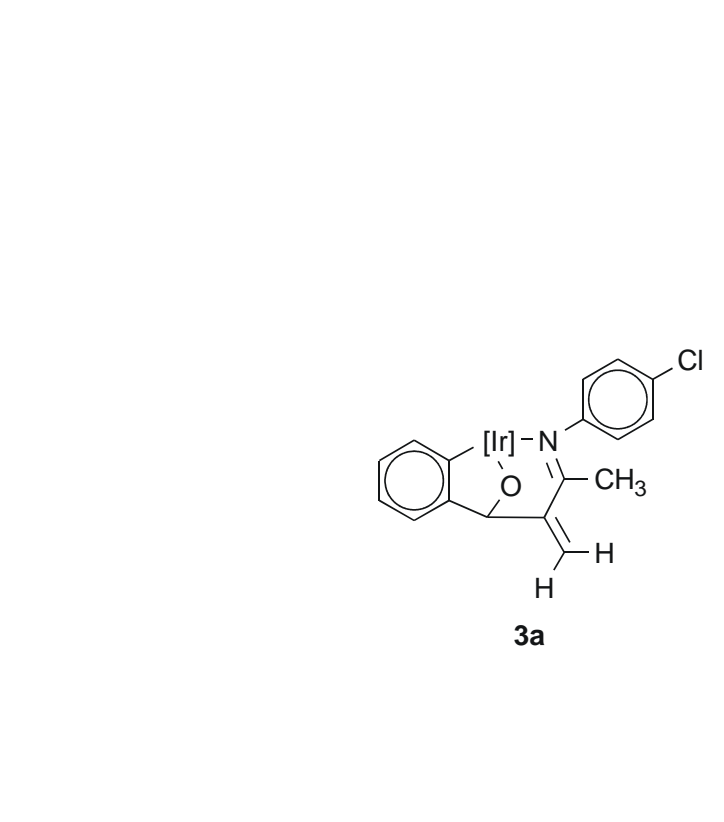

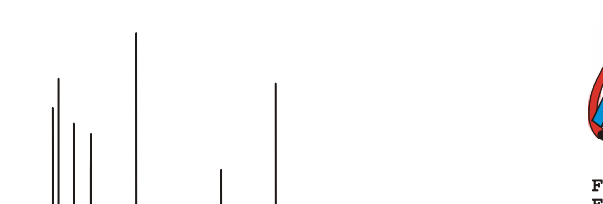

Q UEDL

Filename = VERONICA204_spectrum$\begin{array}{ll}\text { Experiment } & =\text { single pulse.exp } \\ \text { Sample_id } & =\text { CIBENAL24085 }\end{array}$

Solvent

Creation_time $=24$-AUG-2005 15:35:13

Current_time $\quad=1$-SEP-2005 21:29:49

Content $\quad=$ Single Pulse Experime

Dim-title

$\begin{array}{ll}\text { Dim_units } & =[\mathrm{ppm}] \\ \text { Dimensions } & =\mathrm{X}\end{array}$

$\begin{array}{ll}\text { Site } & \text { Eclipse+ } 400 \\ \text { Spectrometer } & =\text { DELTANMR }\end{array}$

Field_strength $=9.389766[\mathrm{~T}](400[\mathrm{MHz}]$

X-domain $\quad=1 \mathrm{H}$

$x_{-}$freq

X_points

on $\quad=0.36616006[\mathrm{~Hz}]$

nod_retur

$\begin{array}{ll}\text { X_90_width } & =6.7 \text { [us] } \\ \text { X_acq_time } & =2.73215434[\mathrm{~s}]\end{array}$

$X$-pulse
$=3.35$ [us]

Phase preset $=3$ [us]

$\begin{array}{ll}\text { Recvr_ain } & =17 \\ \text { Relaxation_delay } & =4[\mathrm{~s}] \\ \text { Temp_get } & =22 \text { [dC] } \\ \text { Unblank_time } & =2 \text { [us] }\end{array}$ 


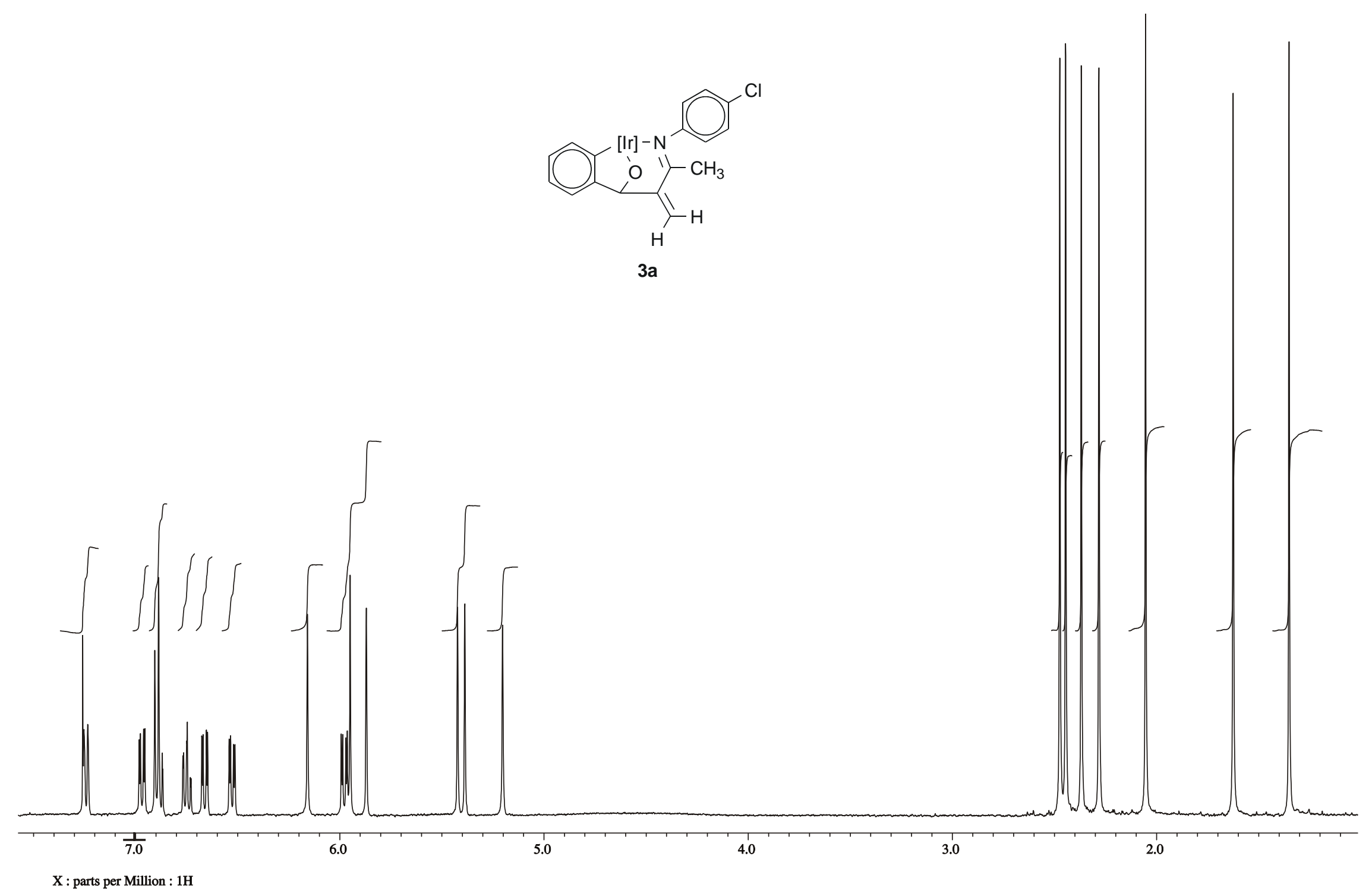




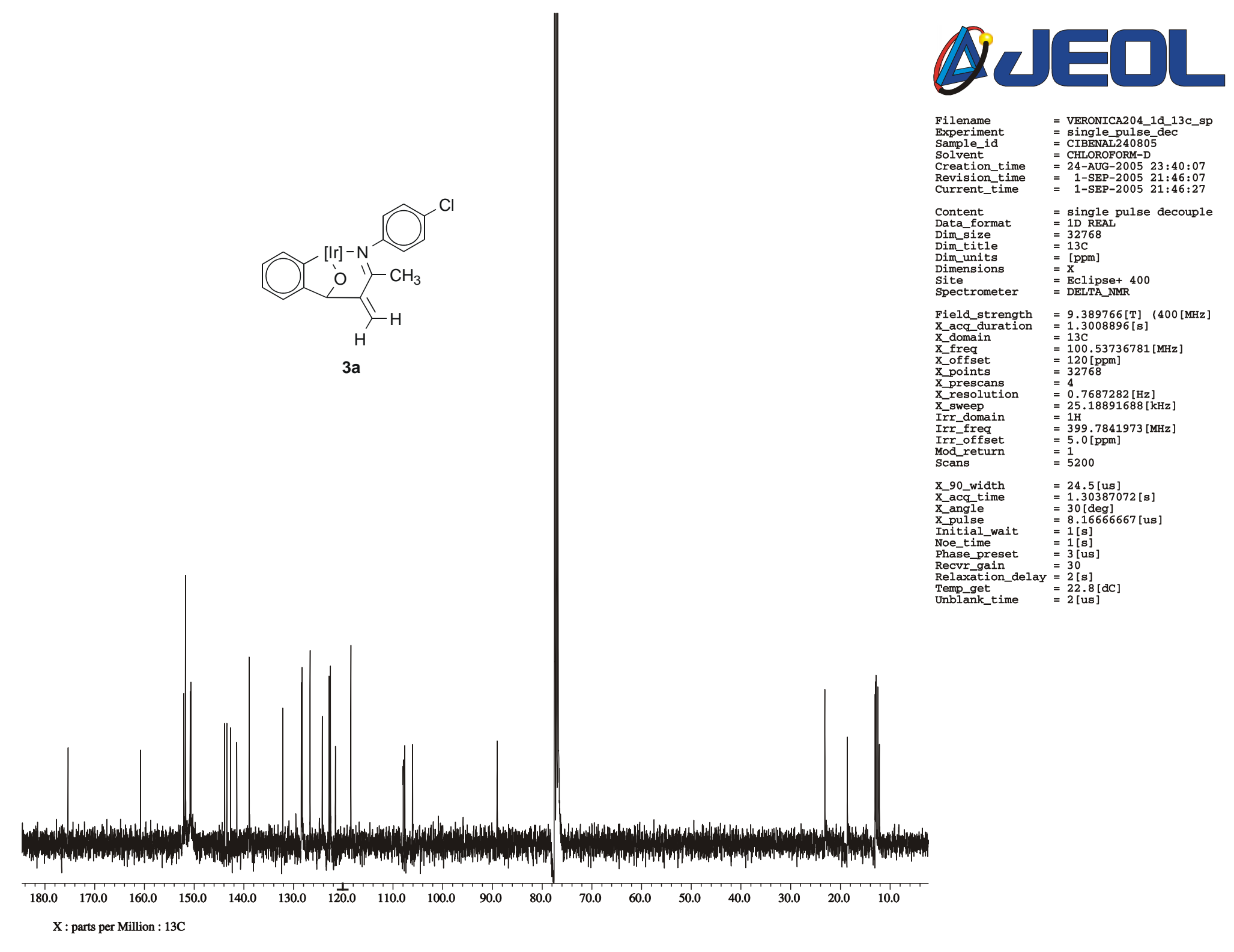




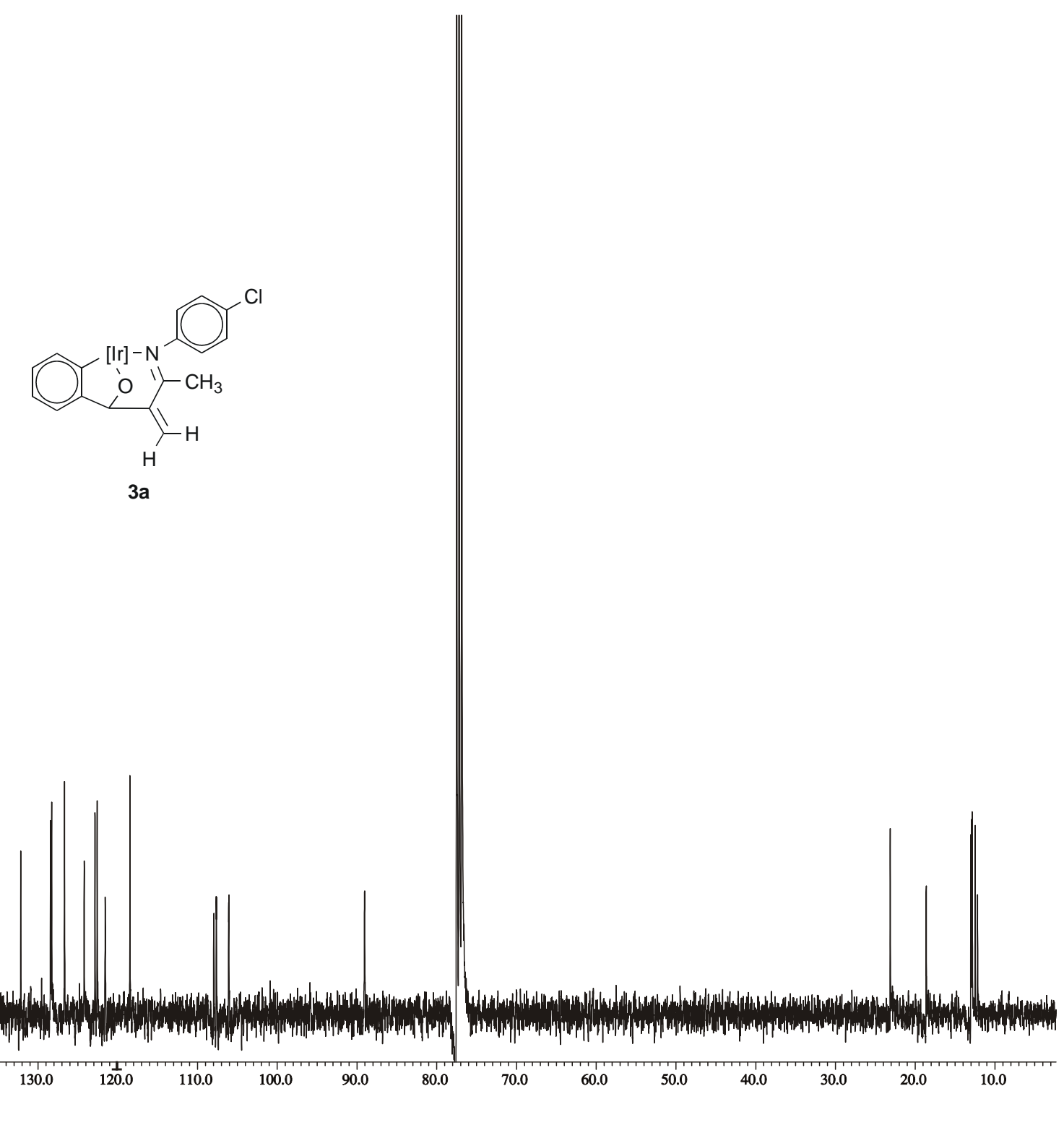




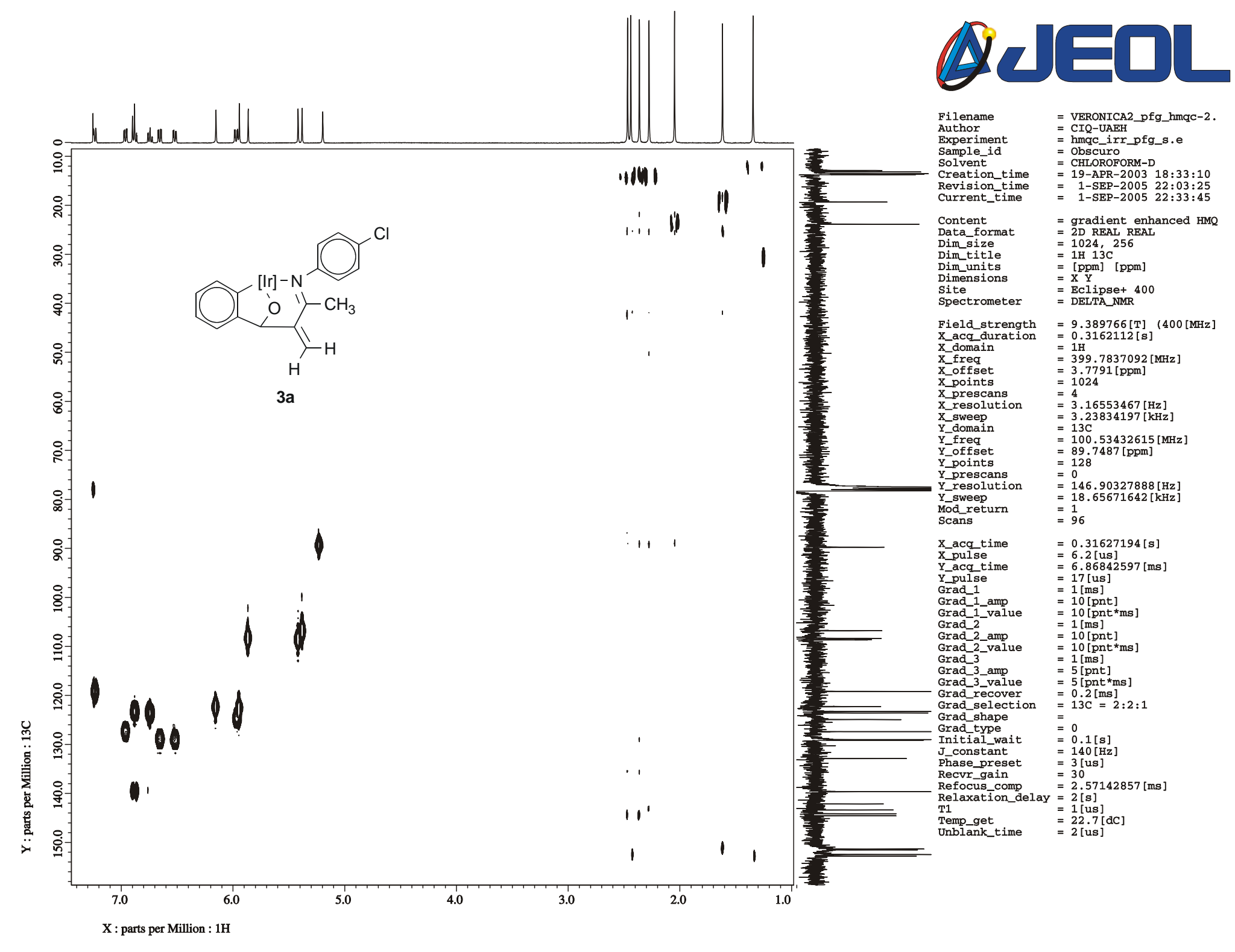




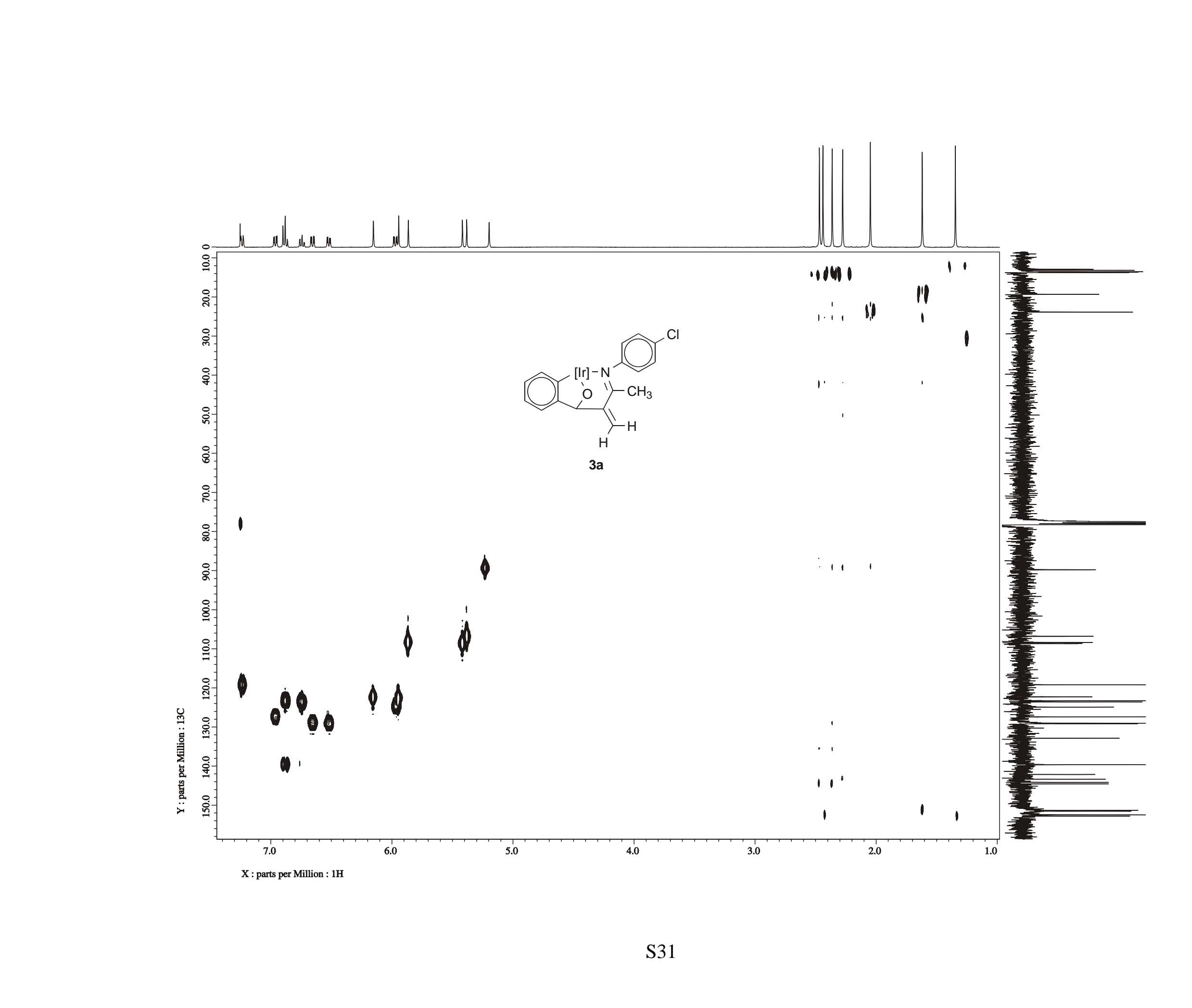




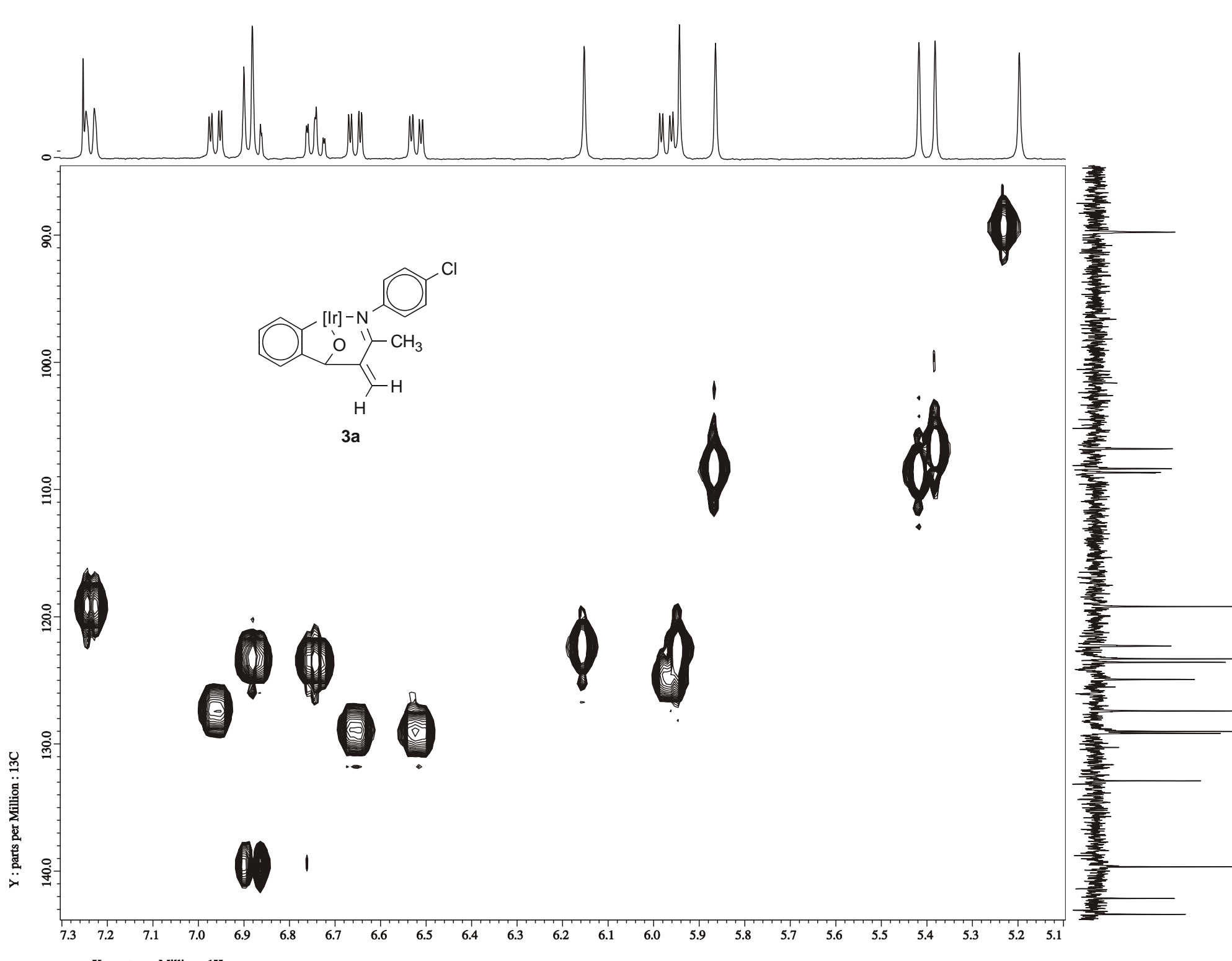




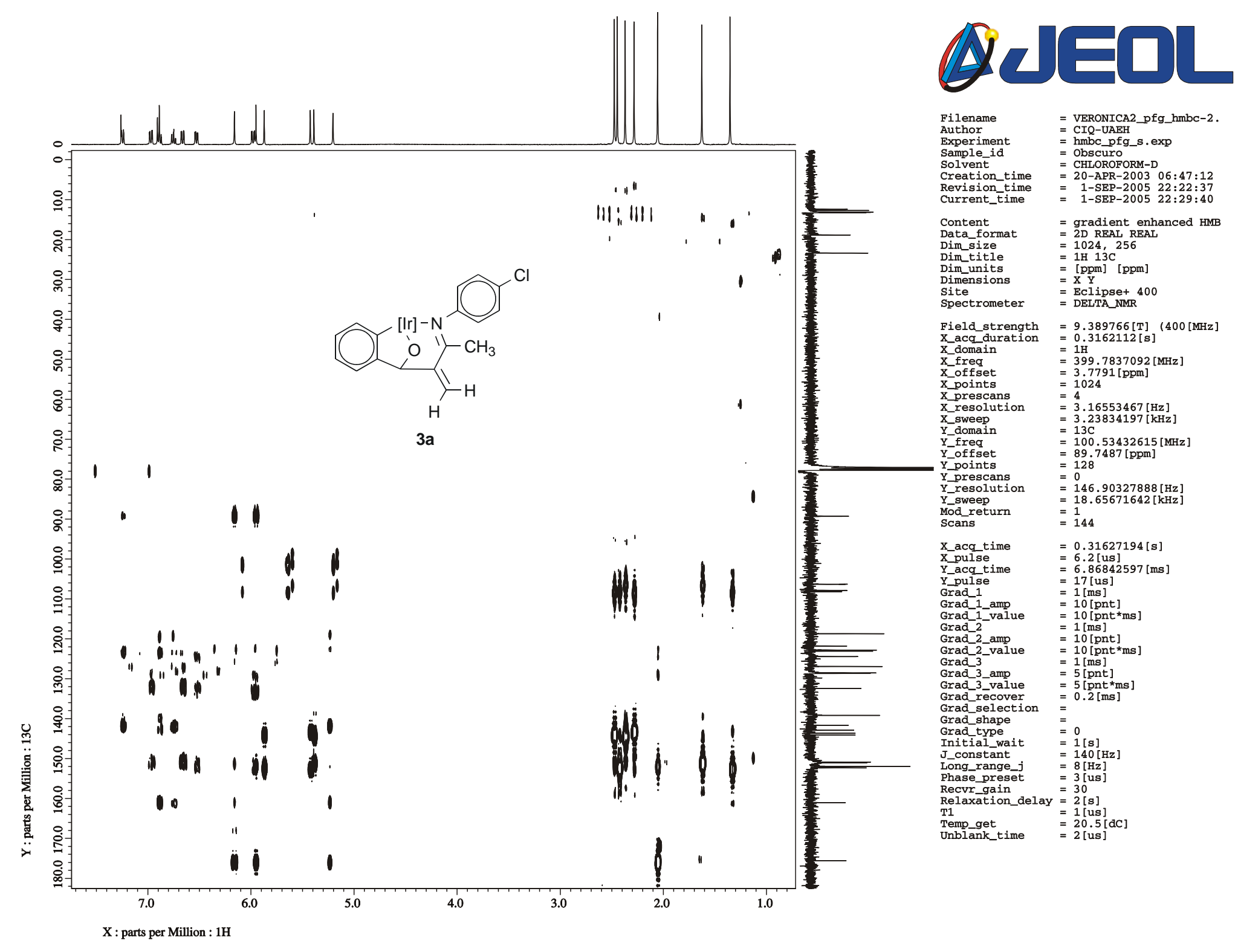




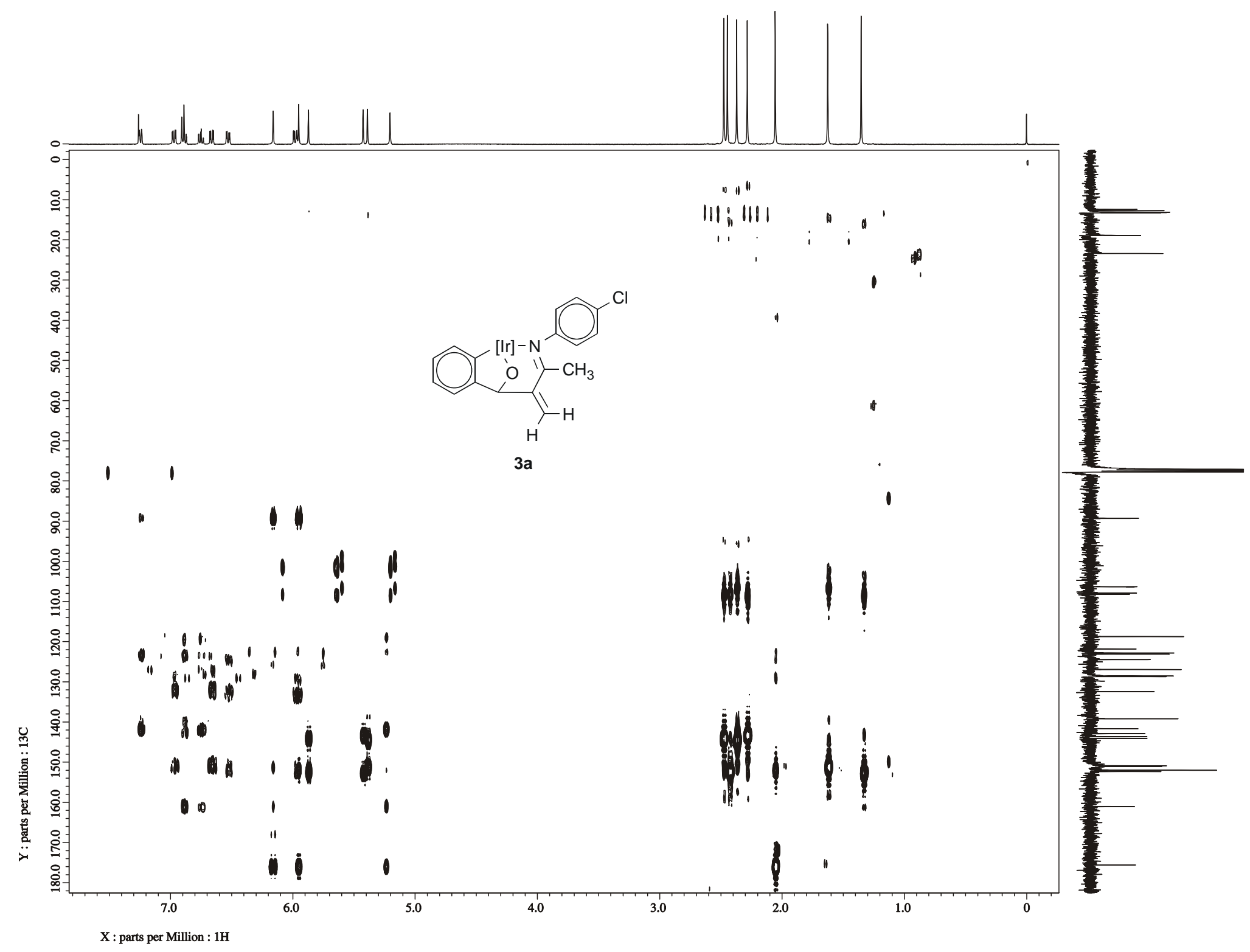




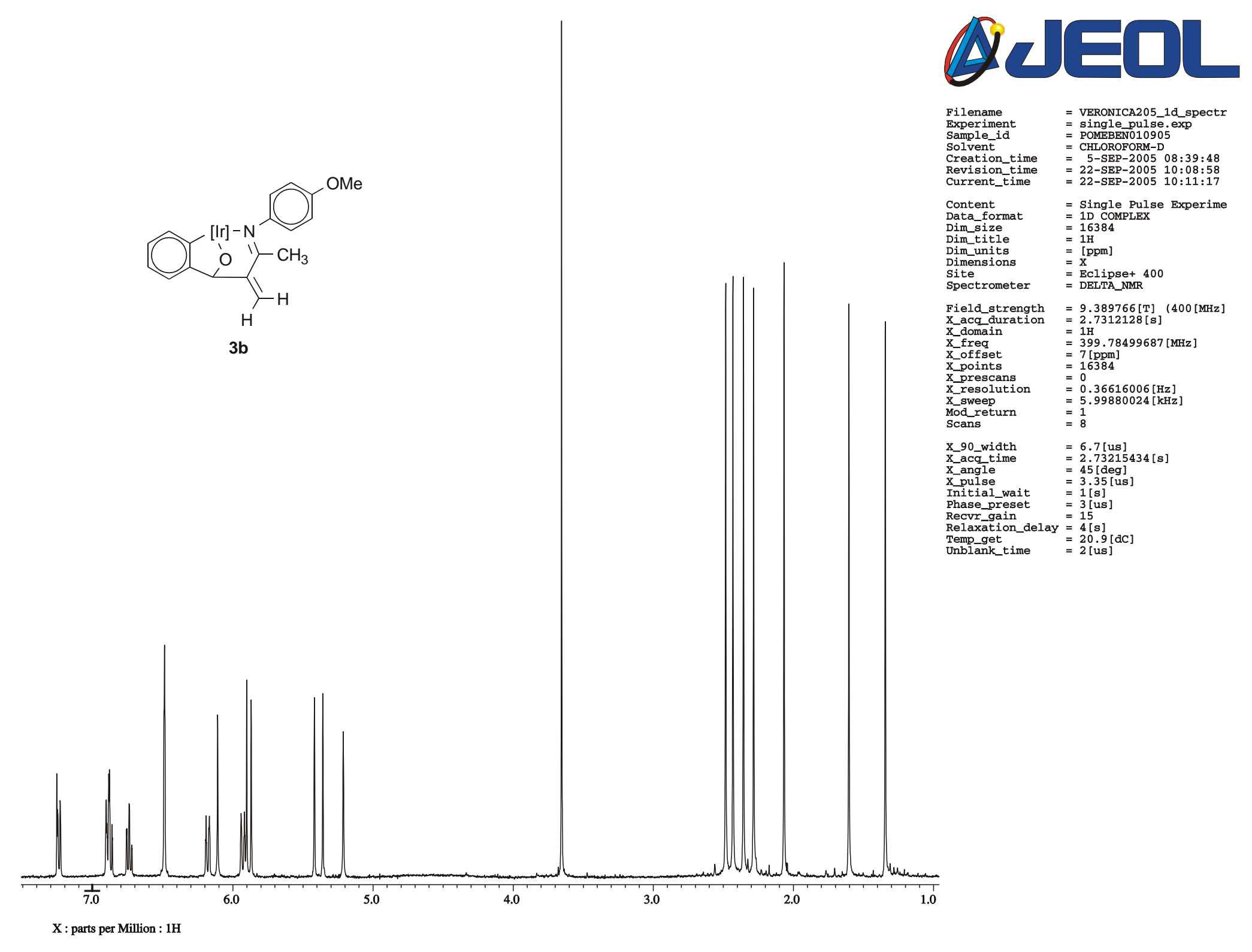




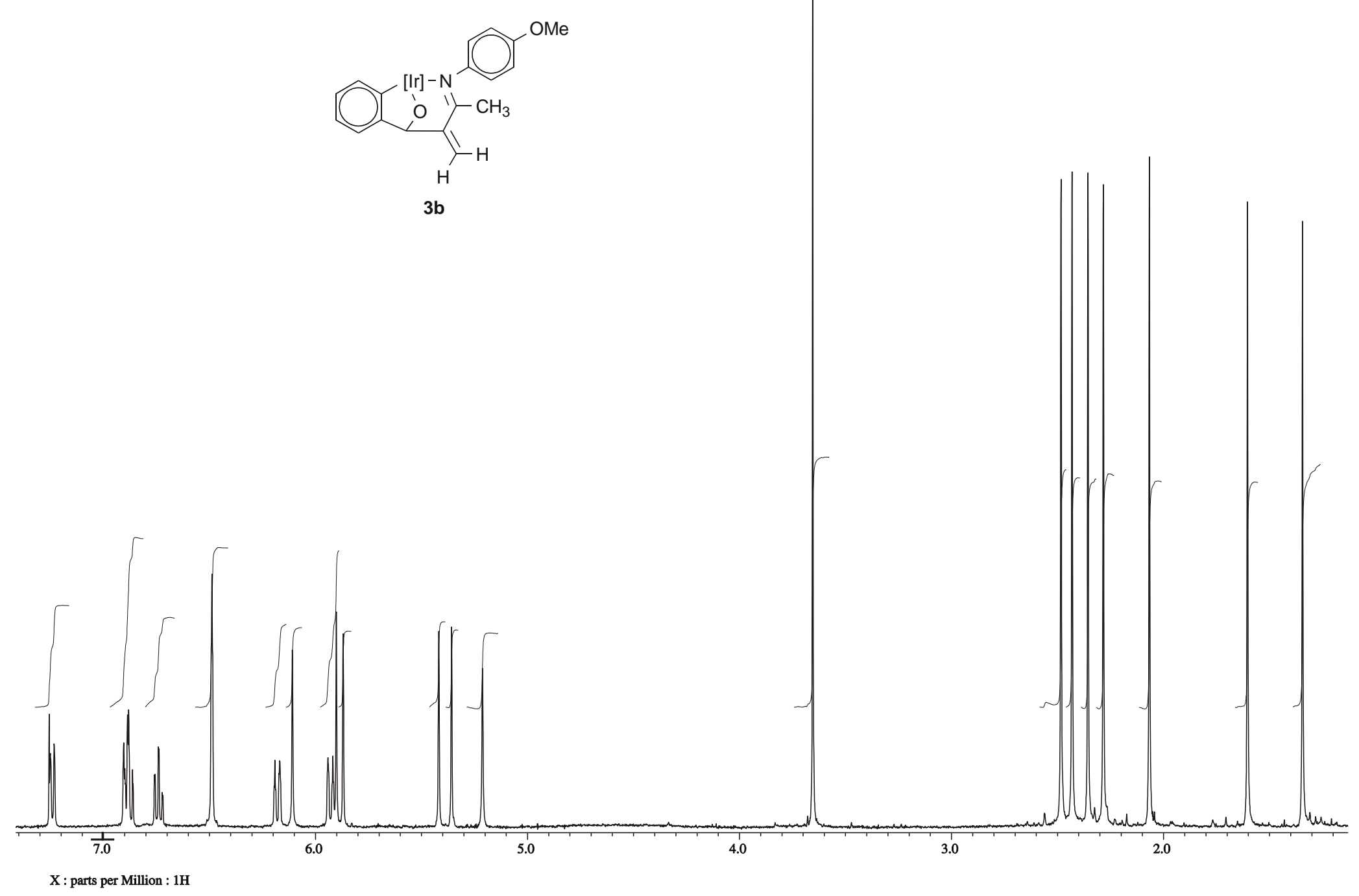




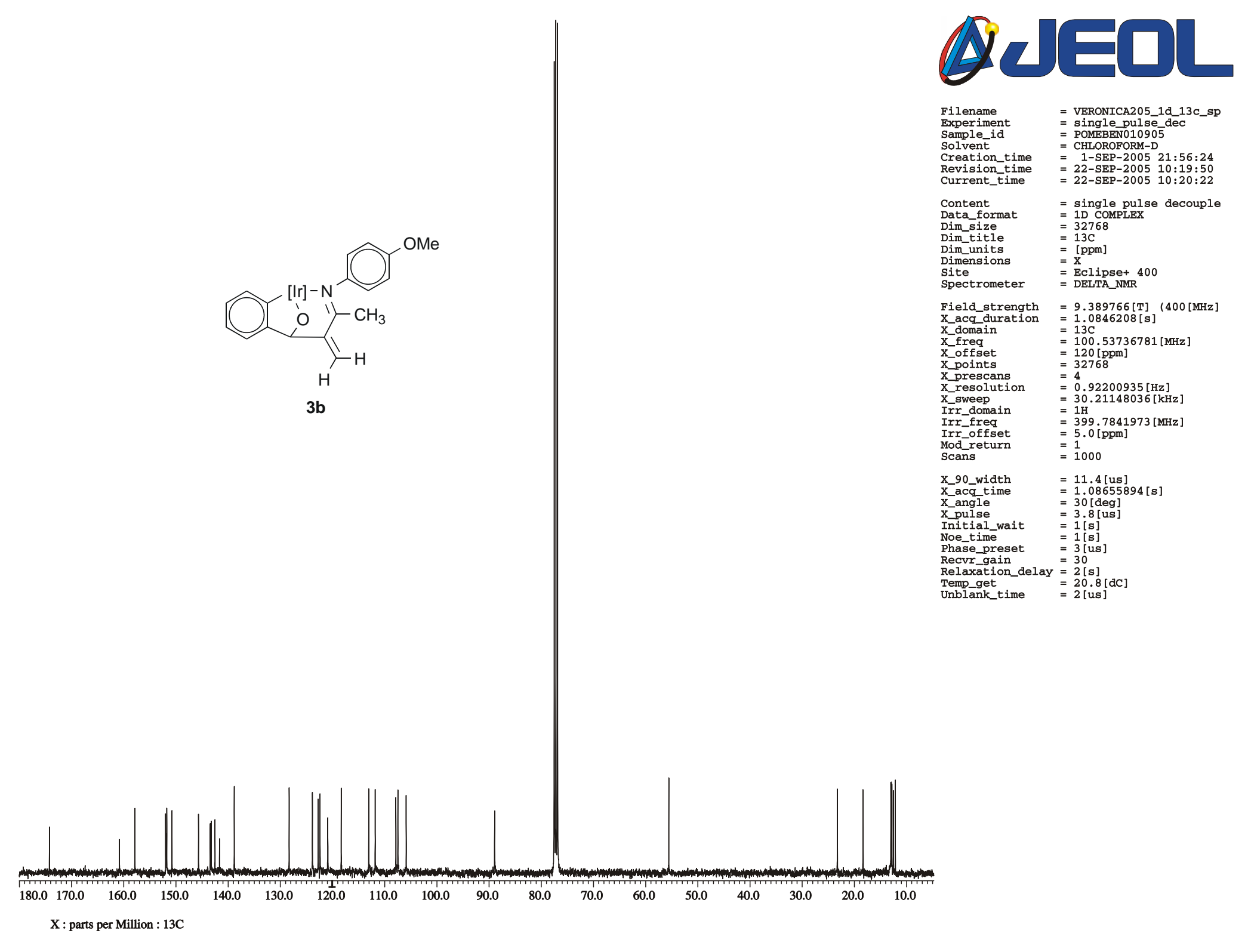



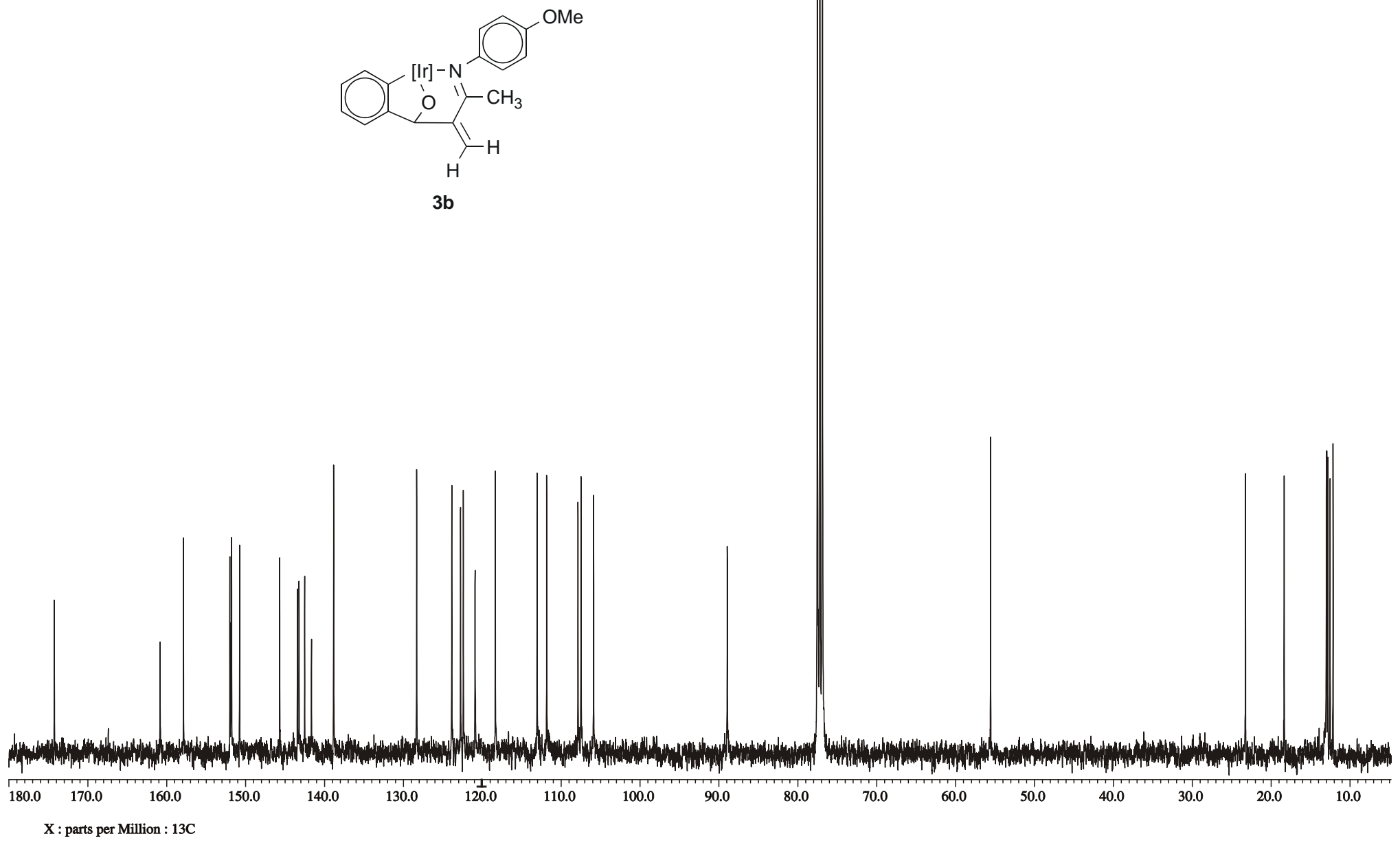


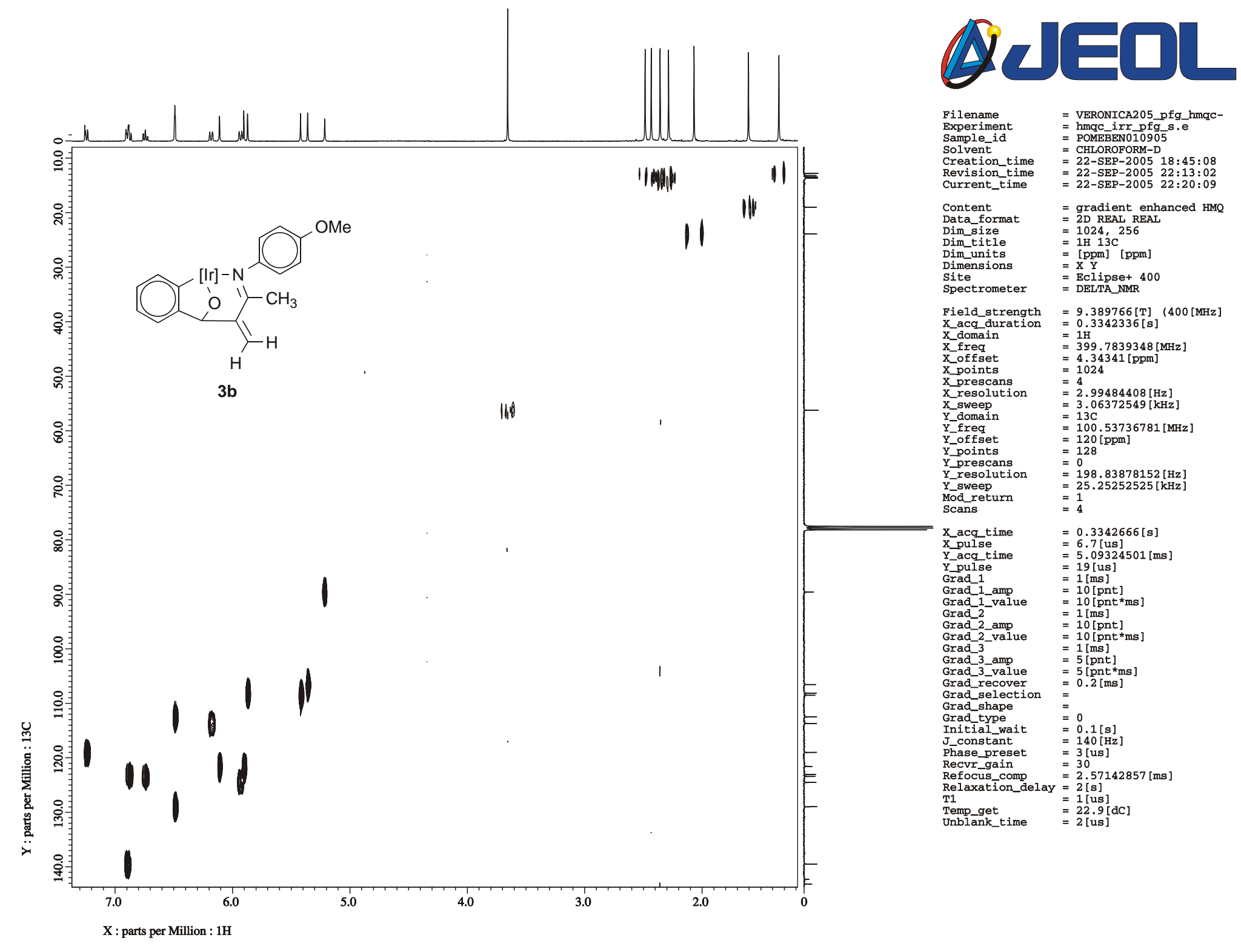




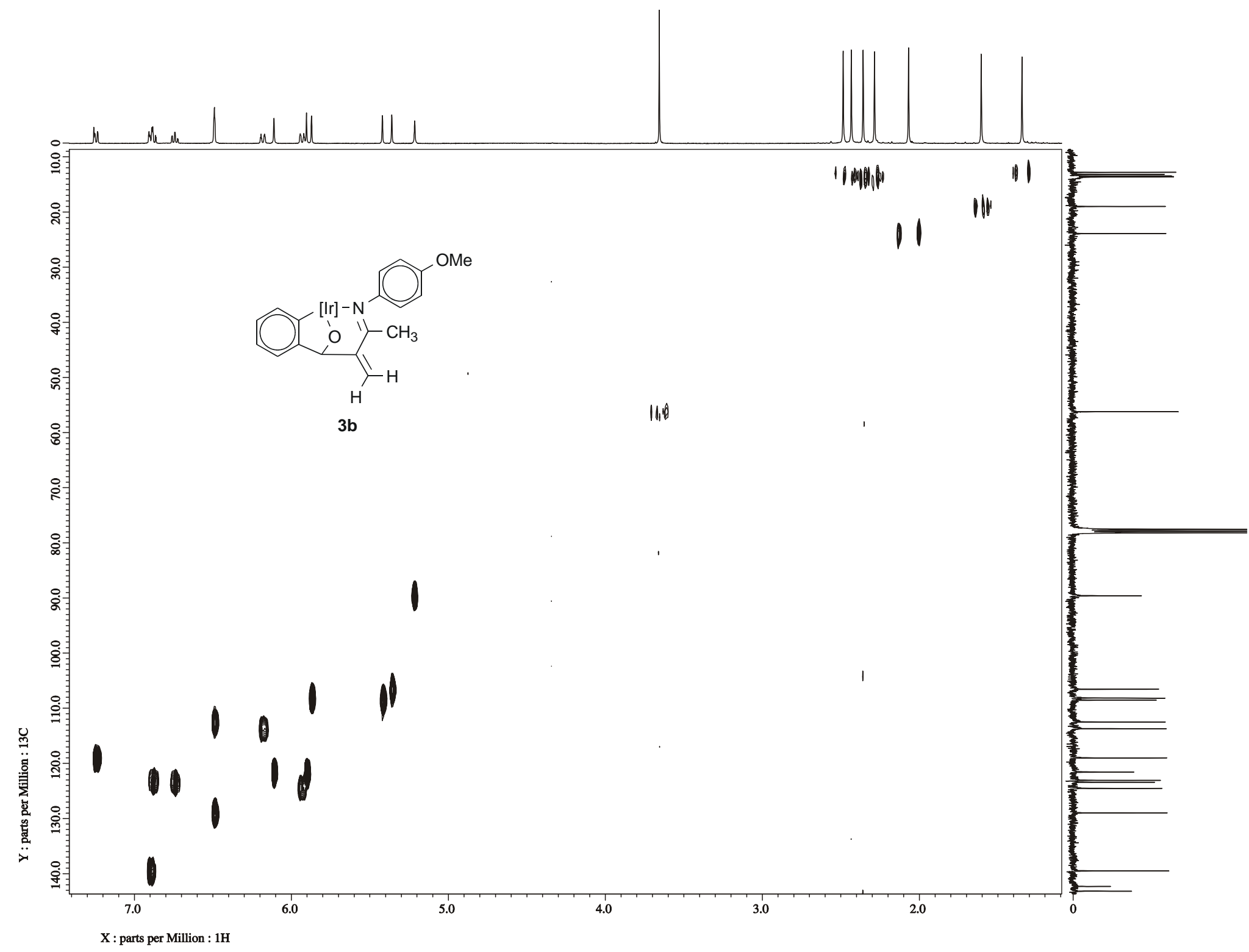




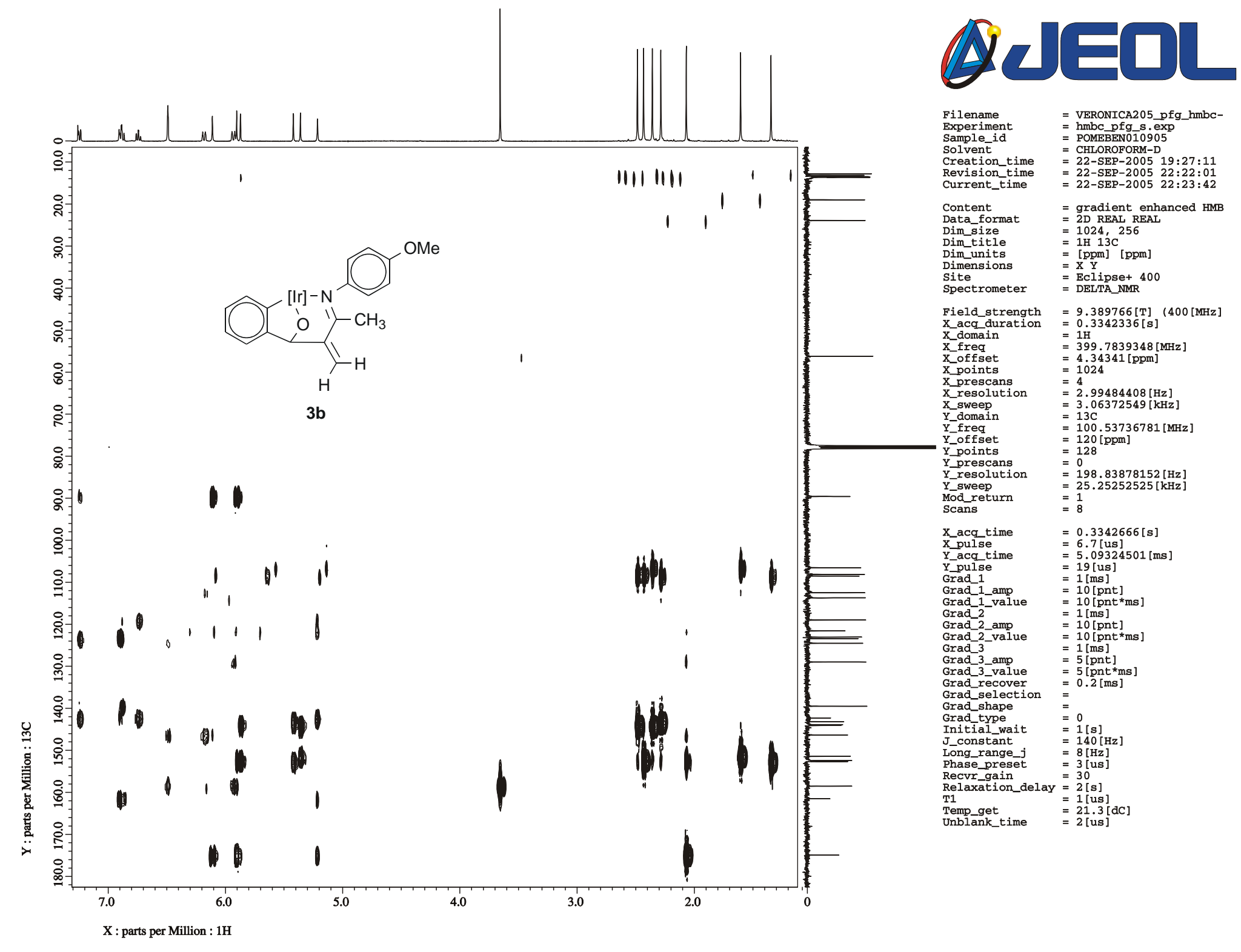




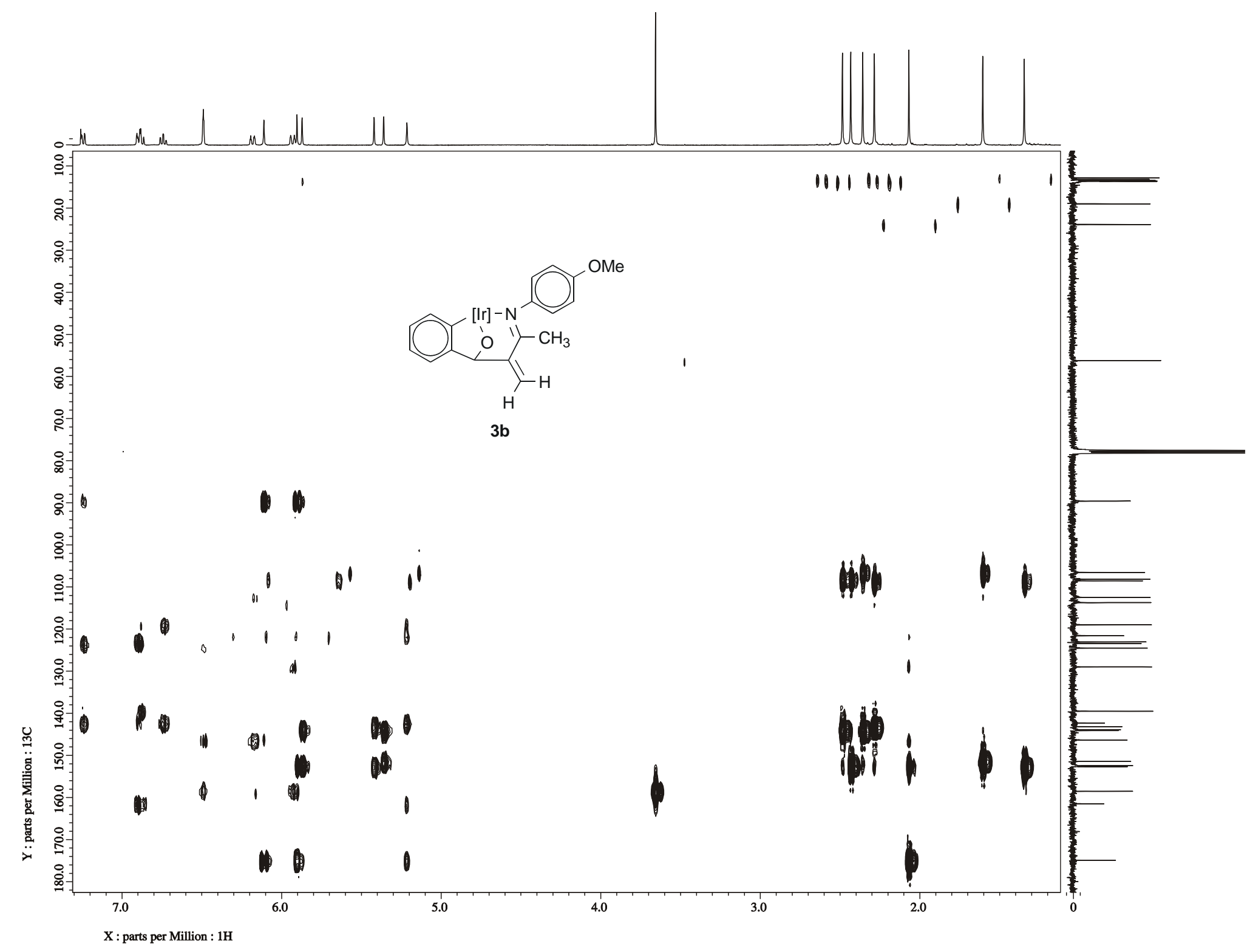




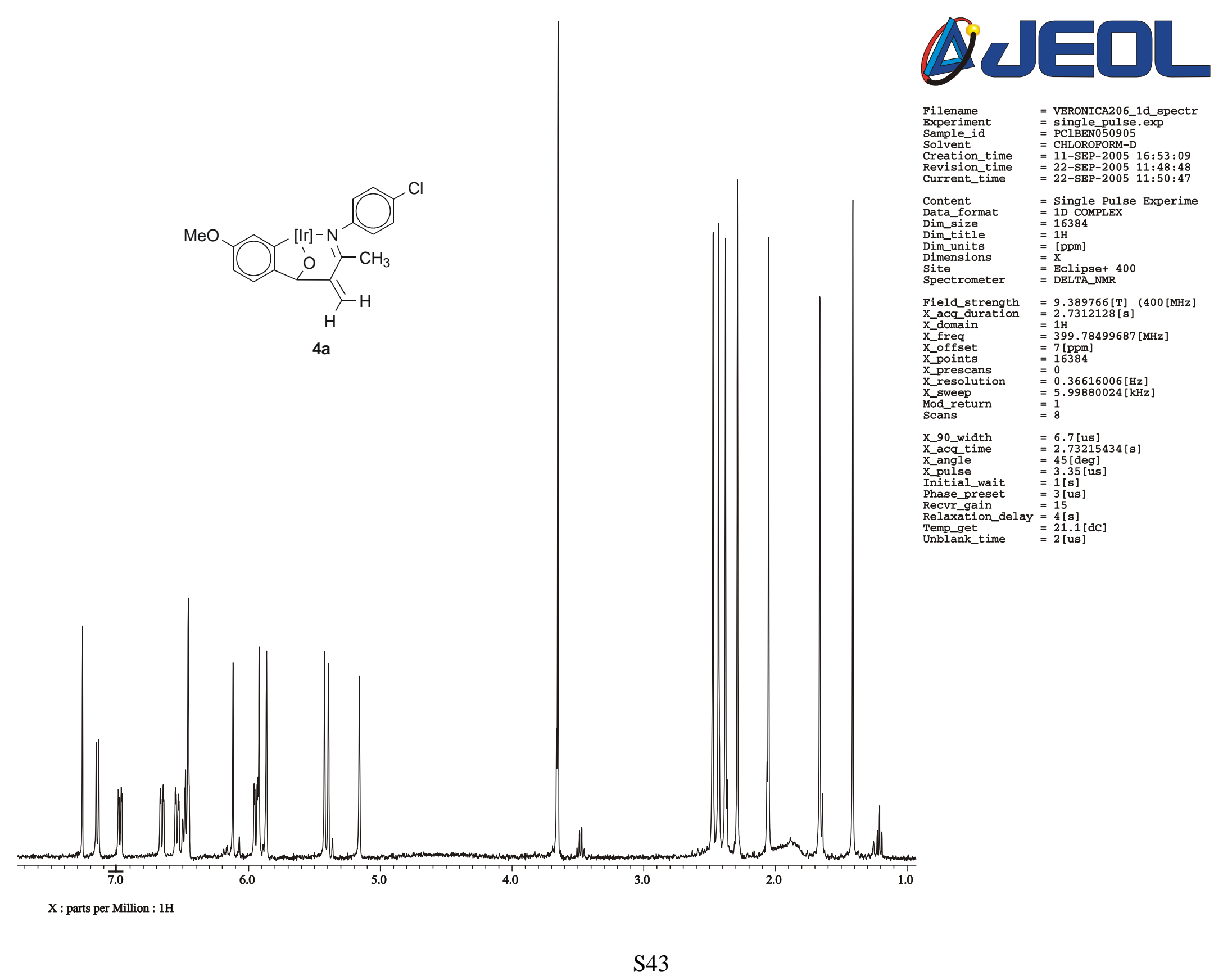




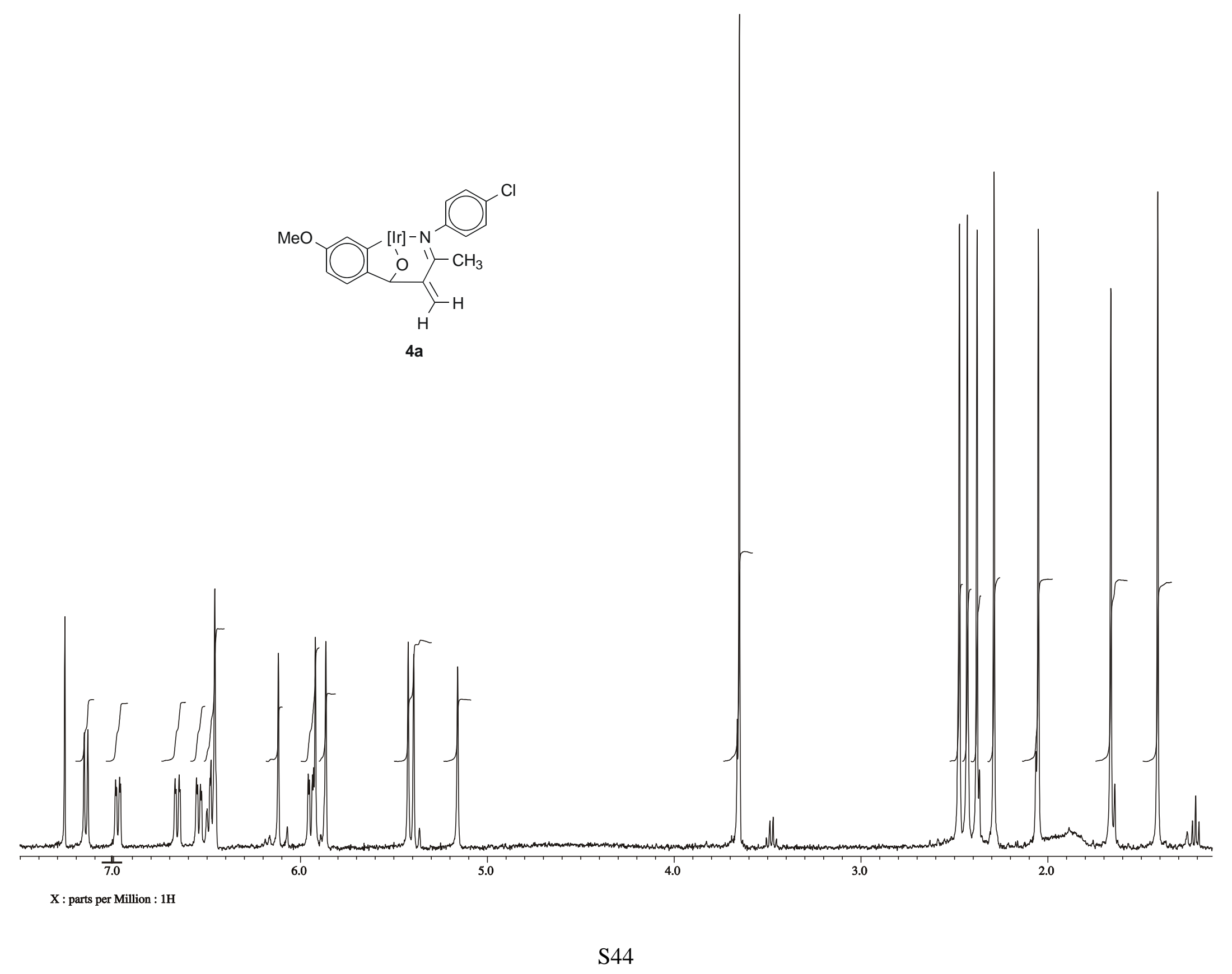




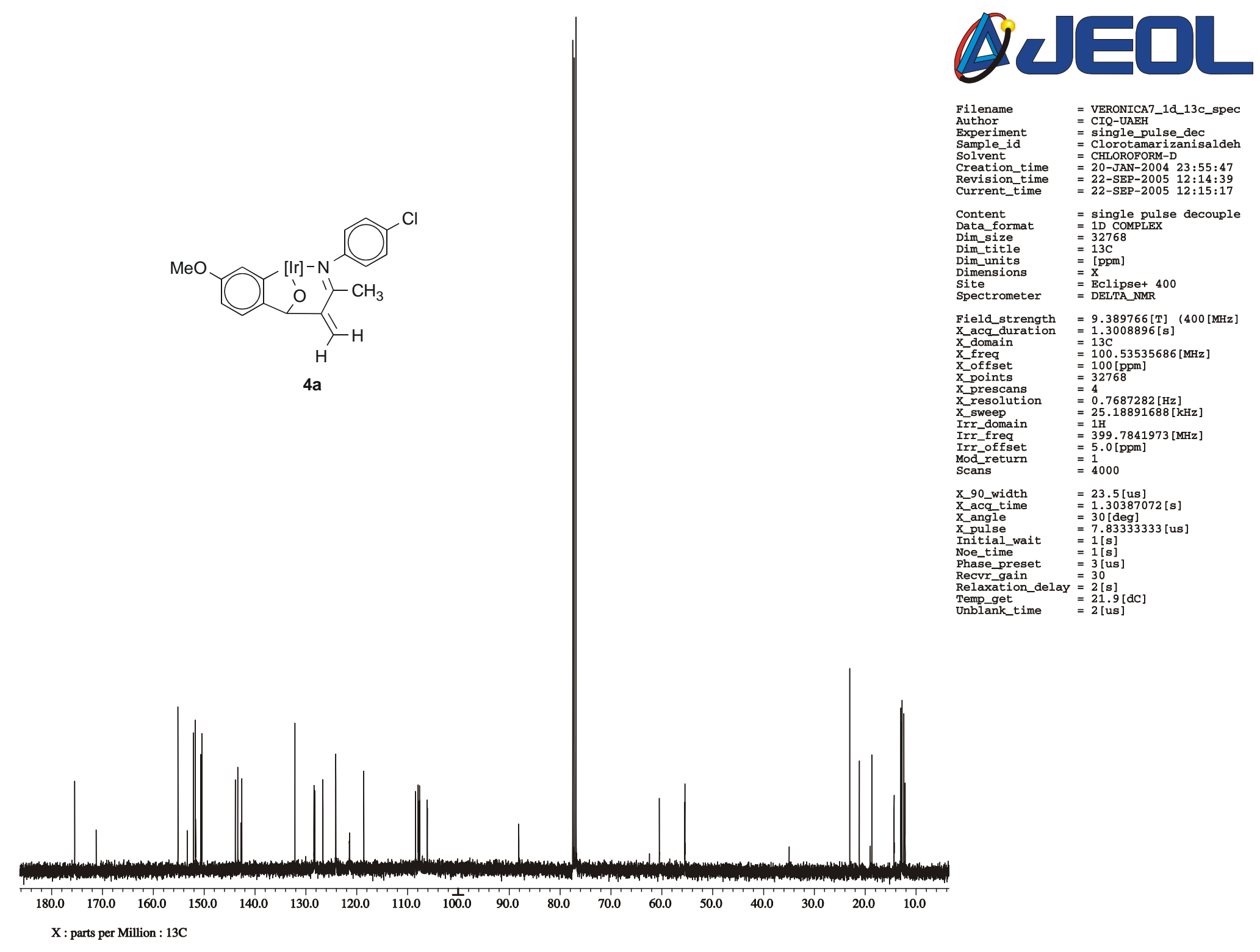




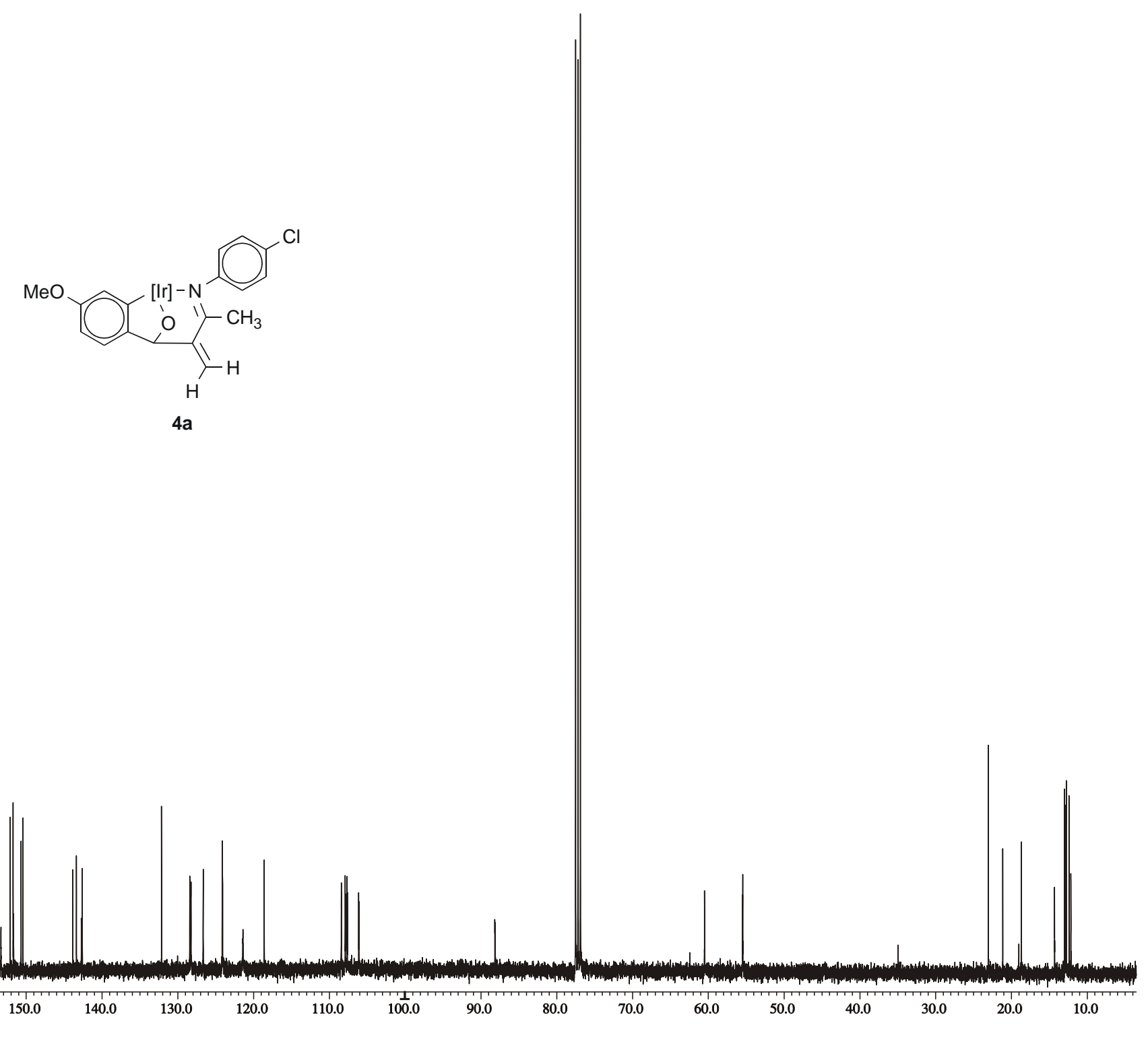




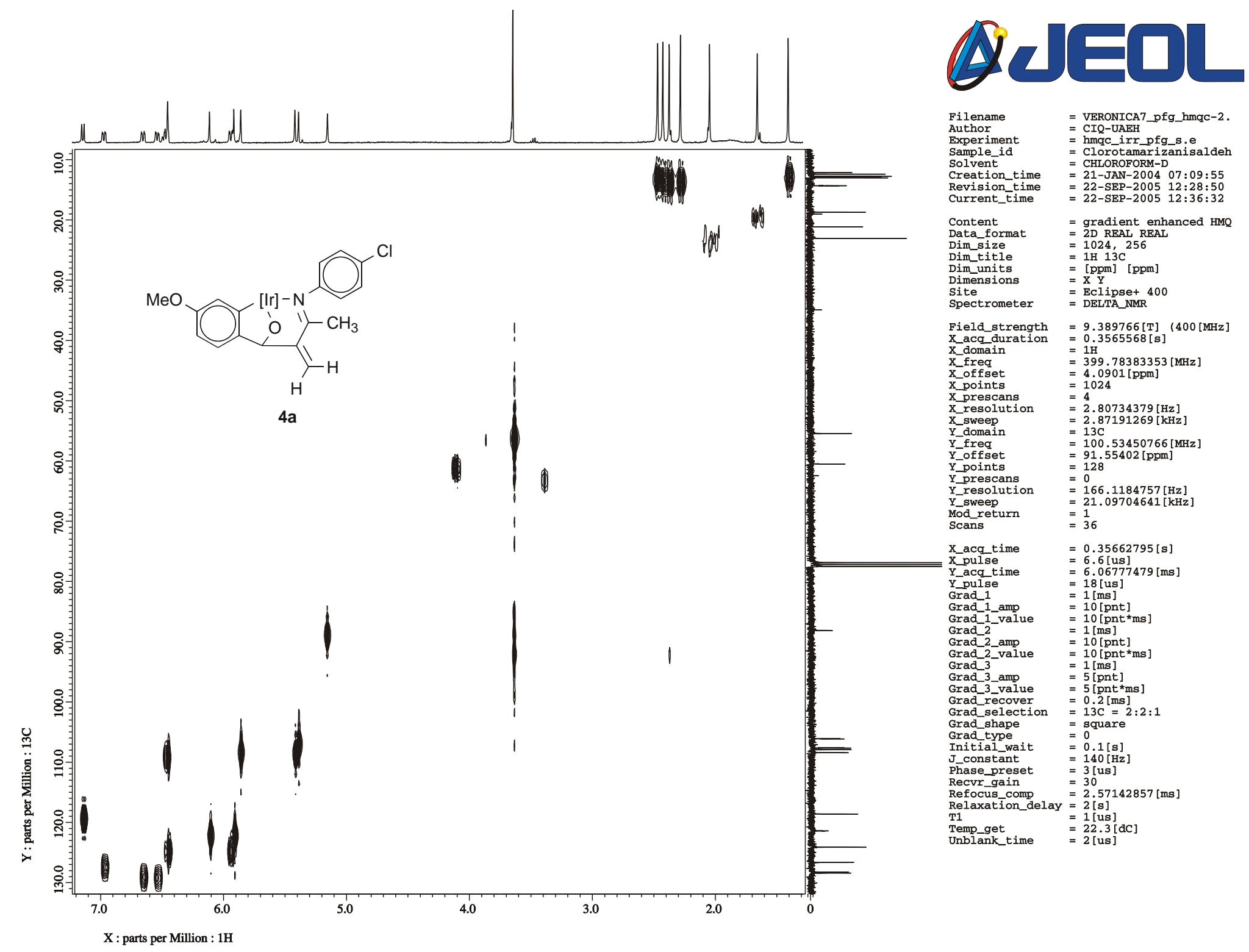




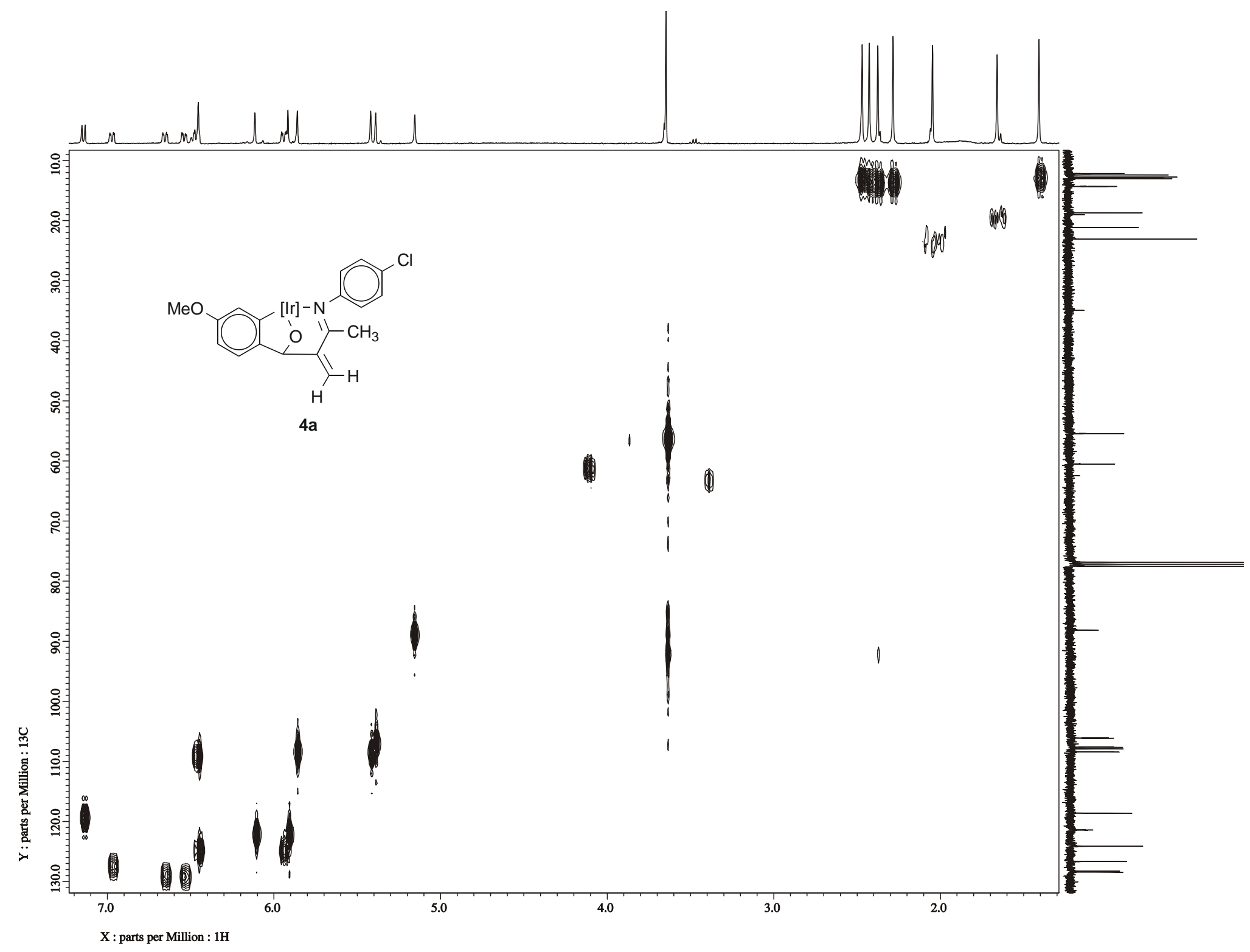




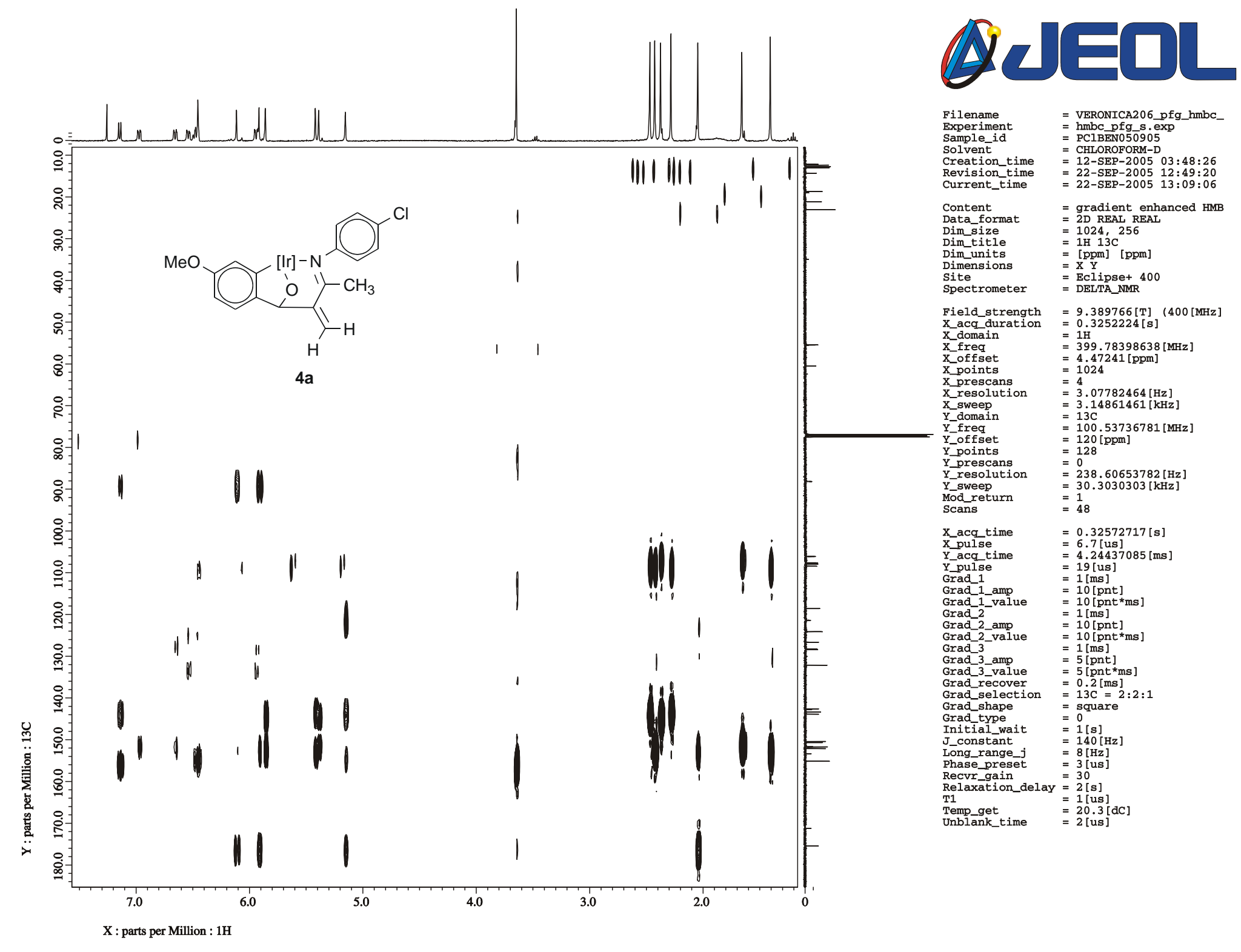




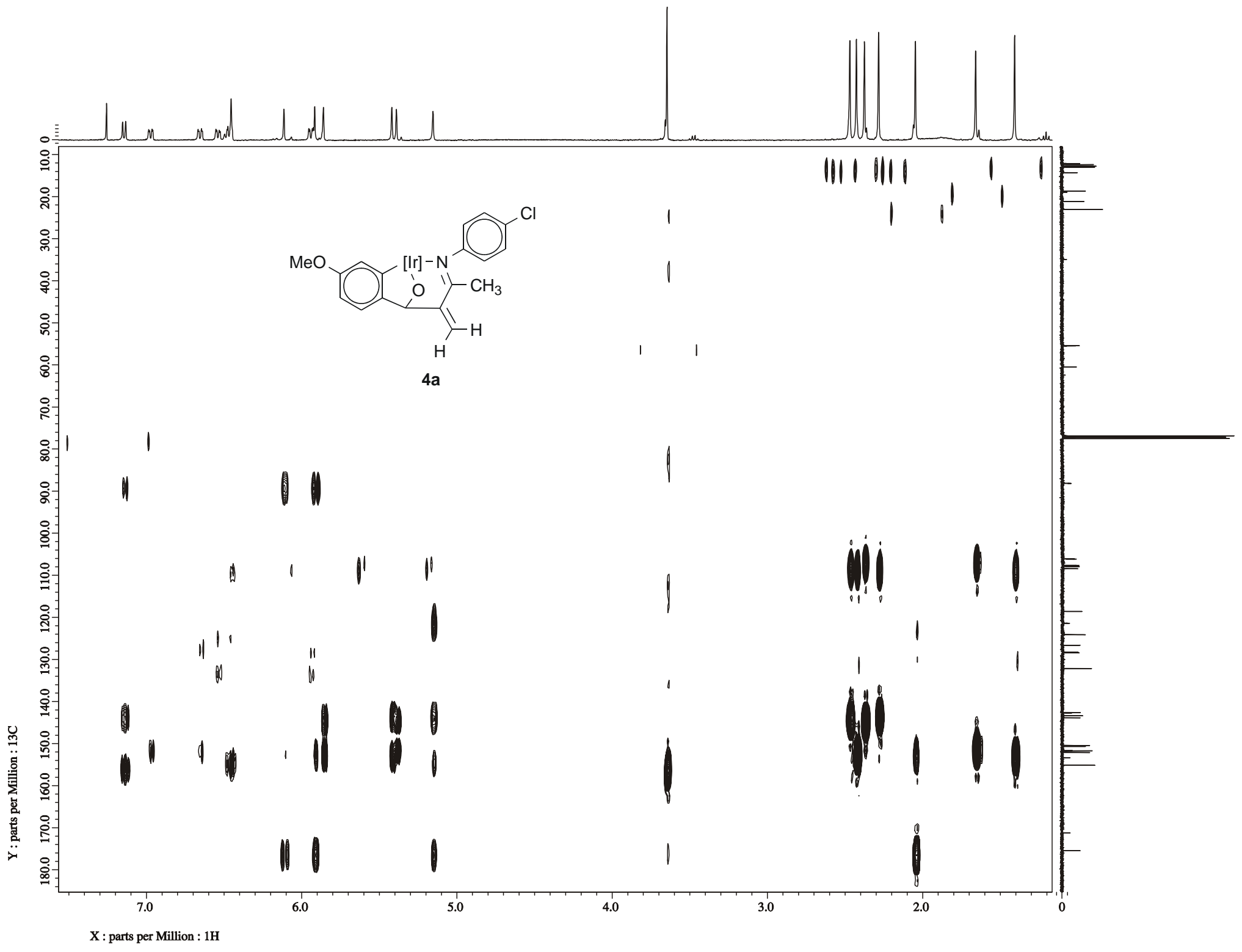

S50 


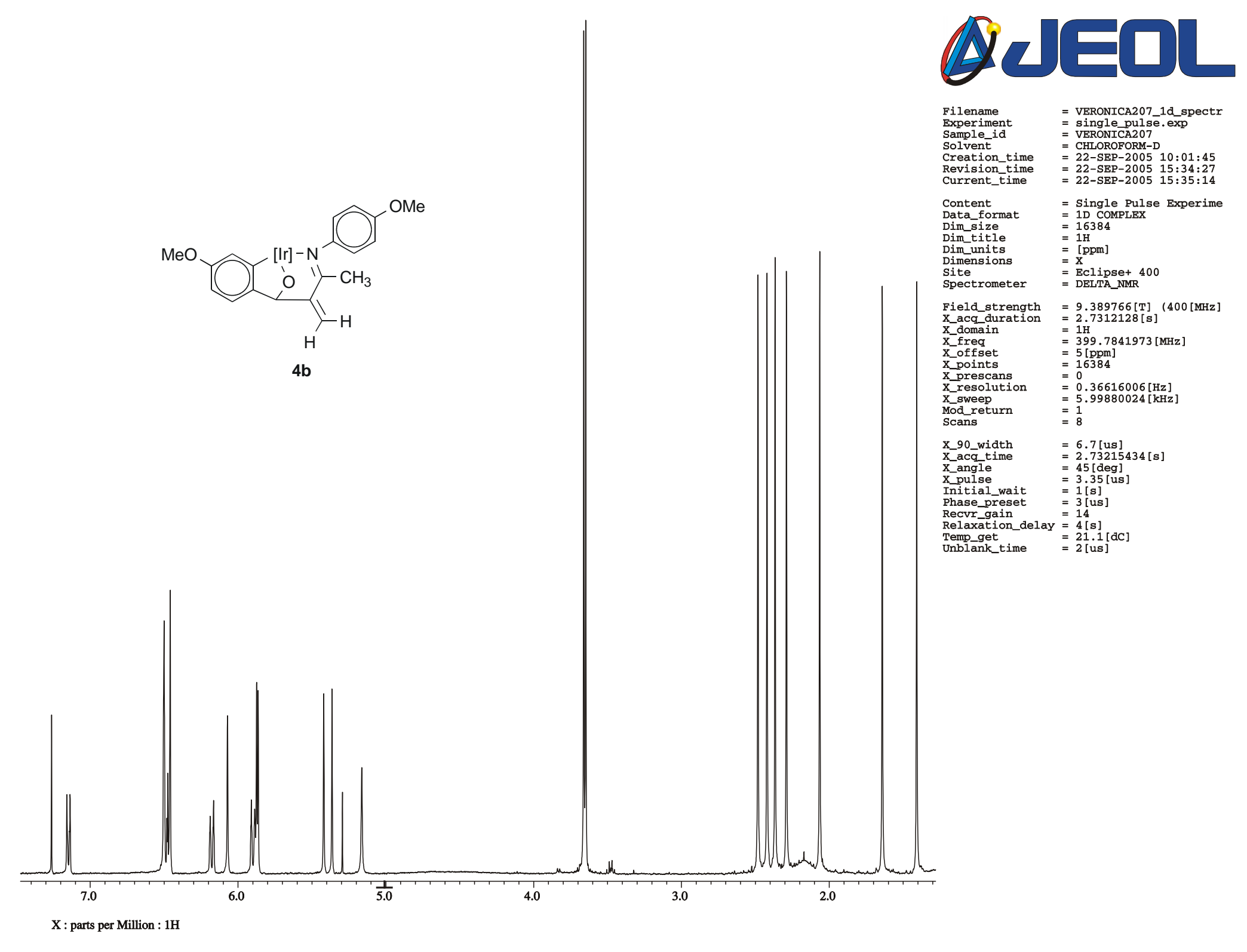




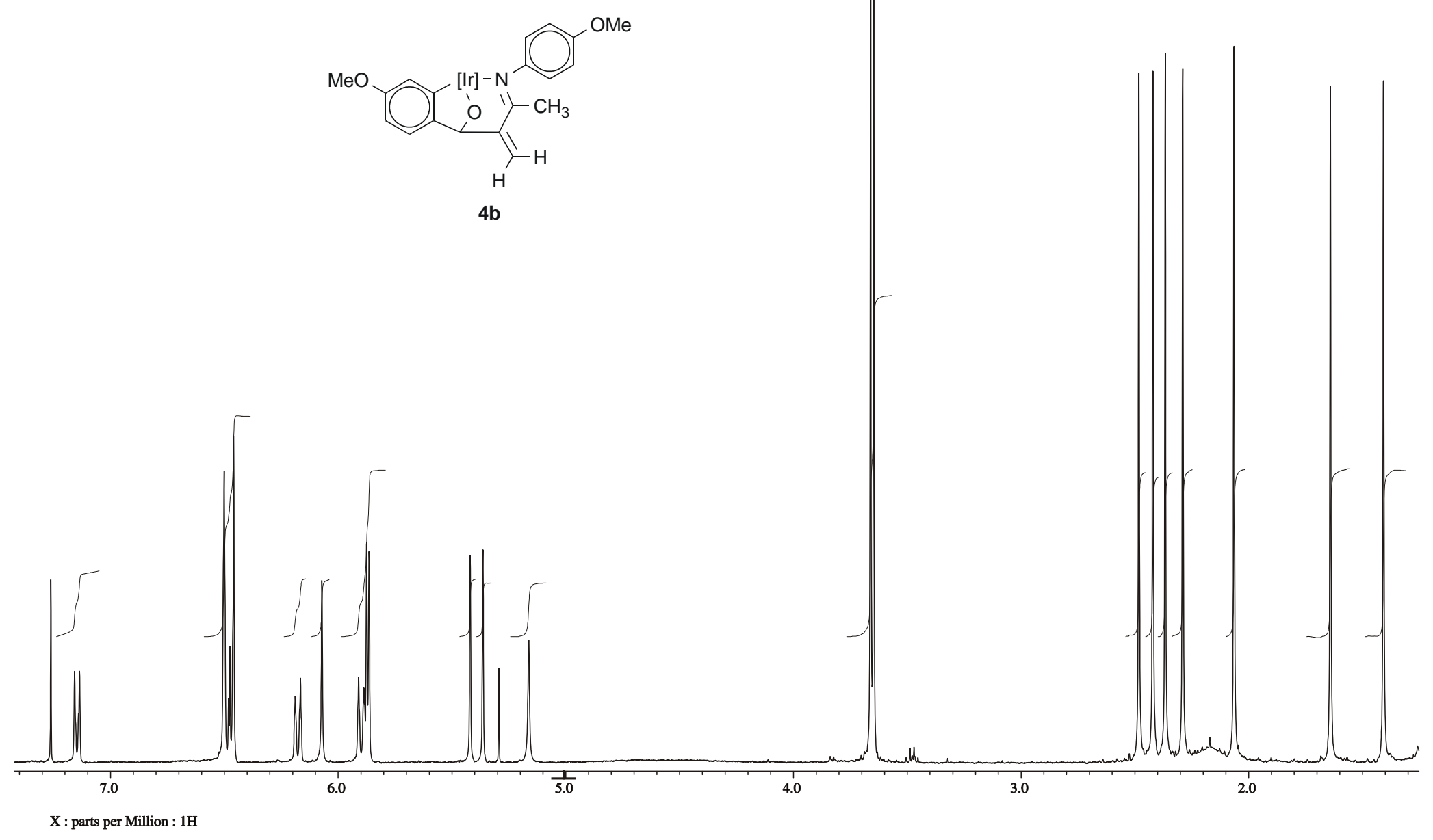




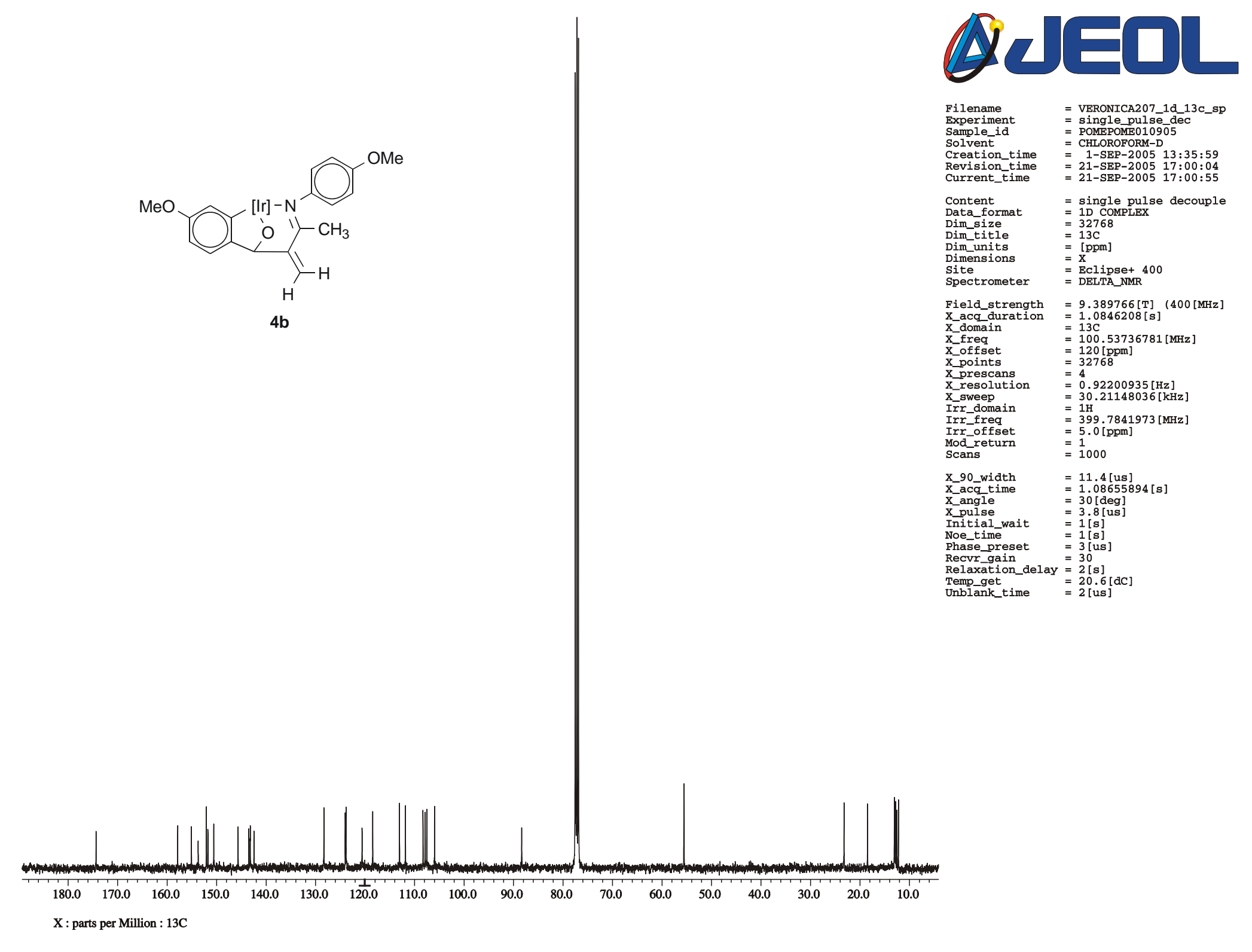




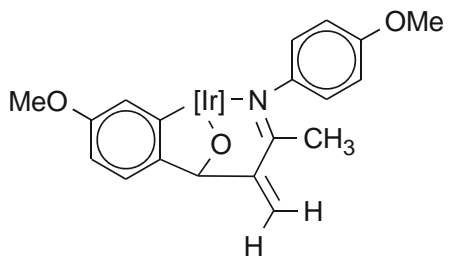

4b

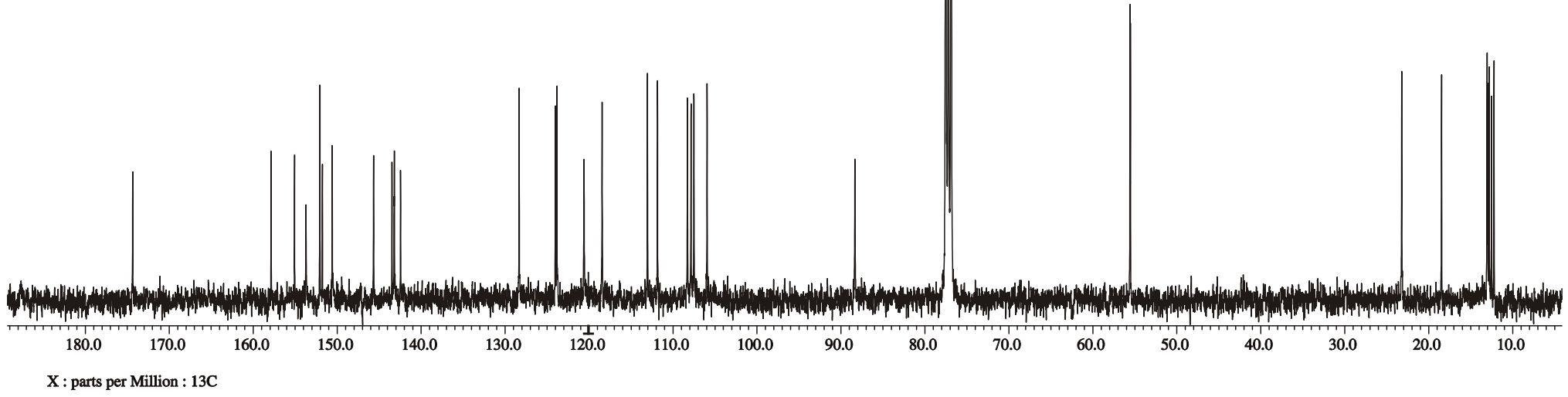

S54 


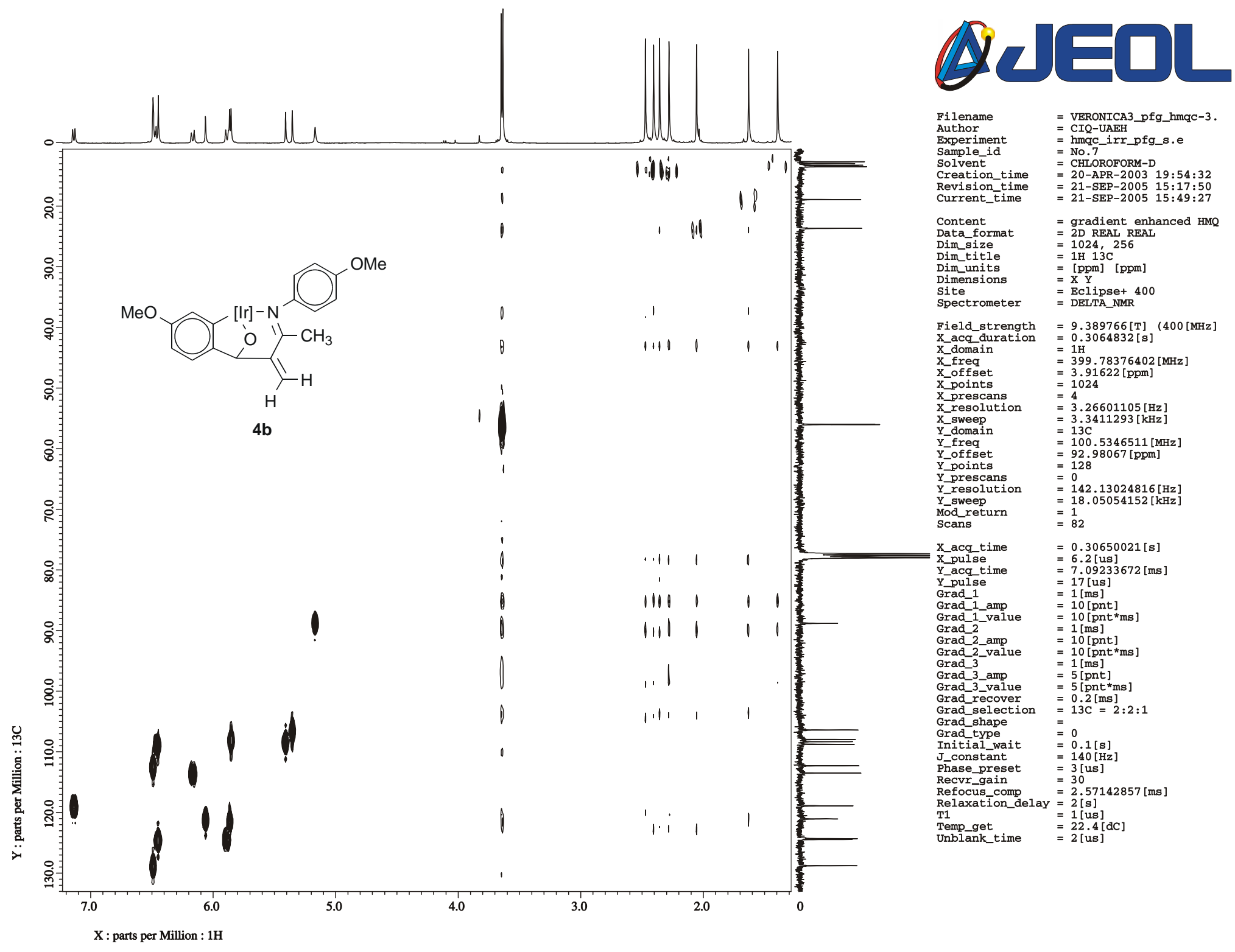




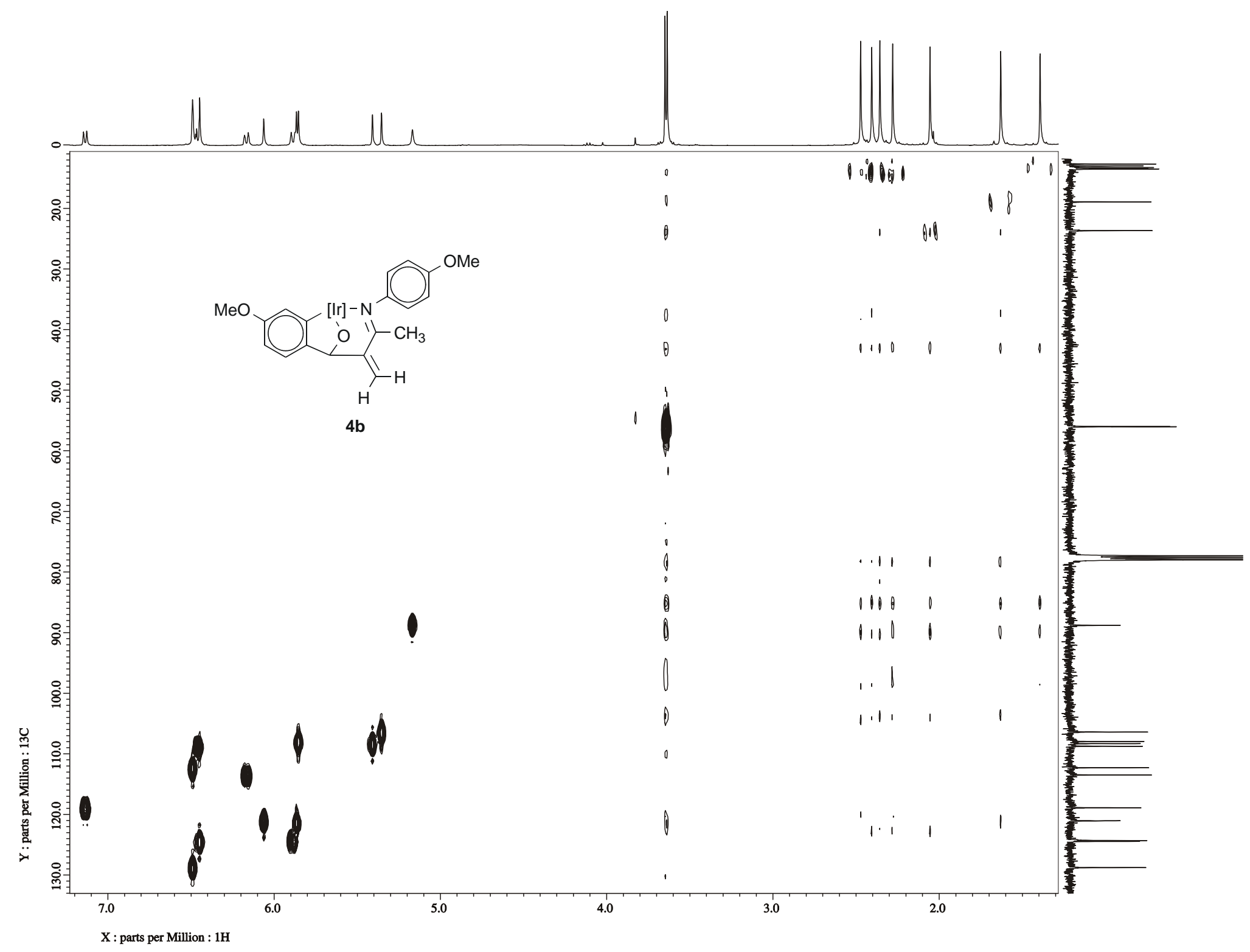




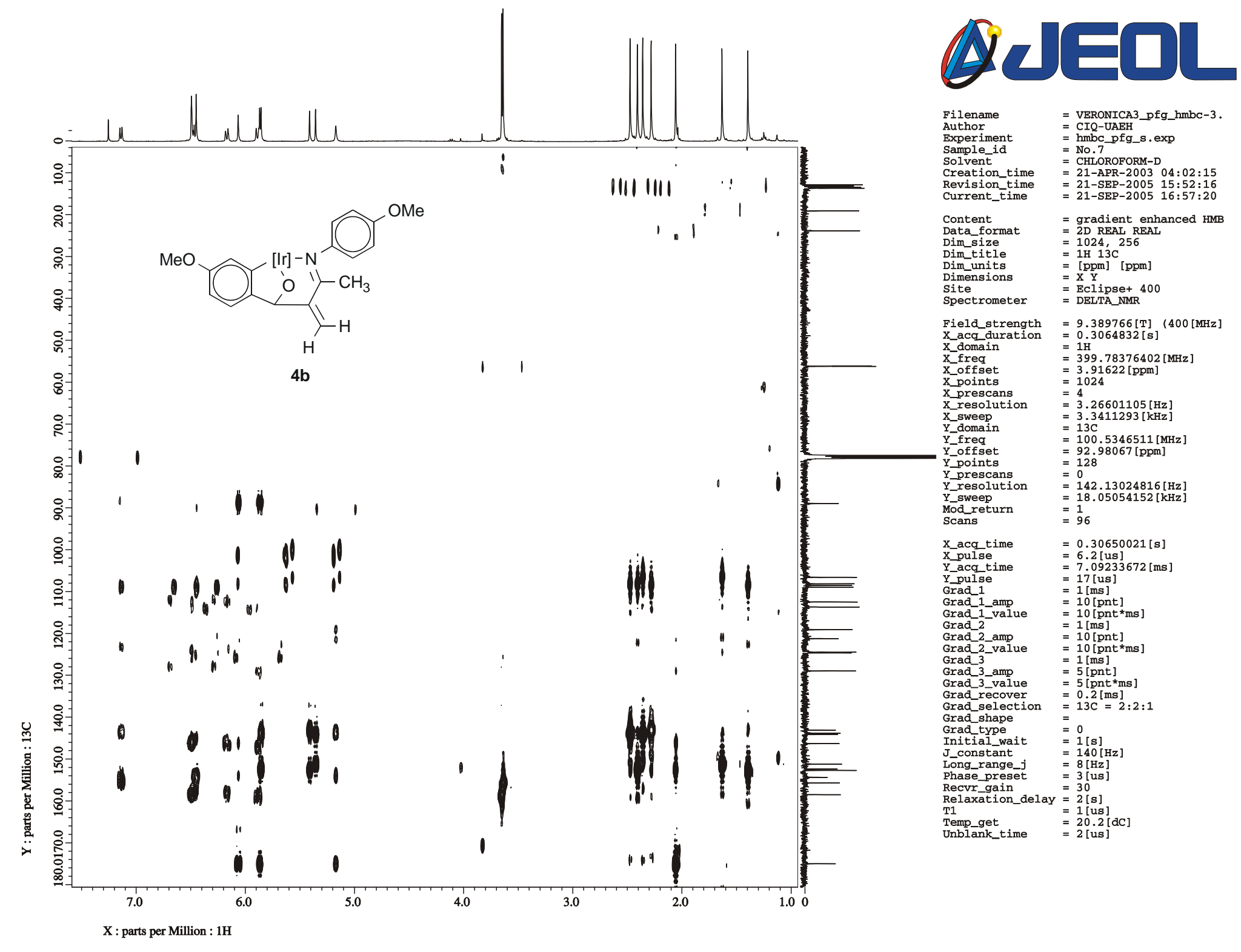




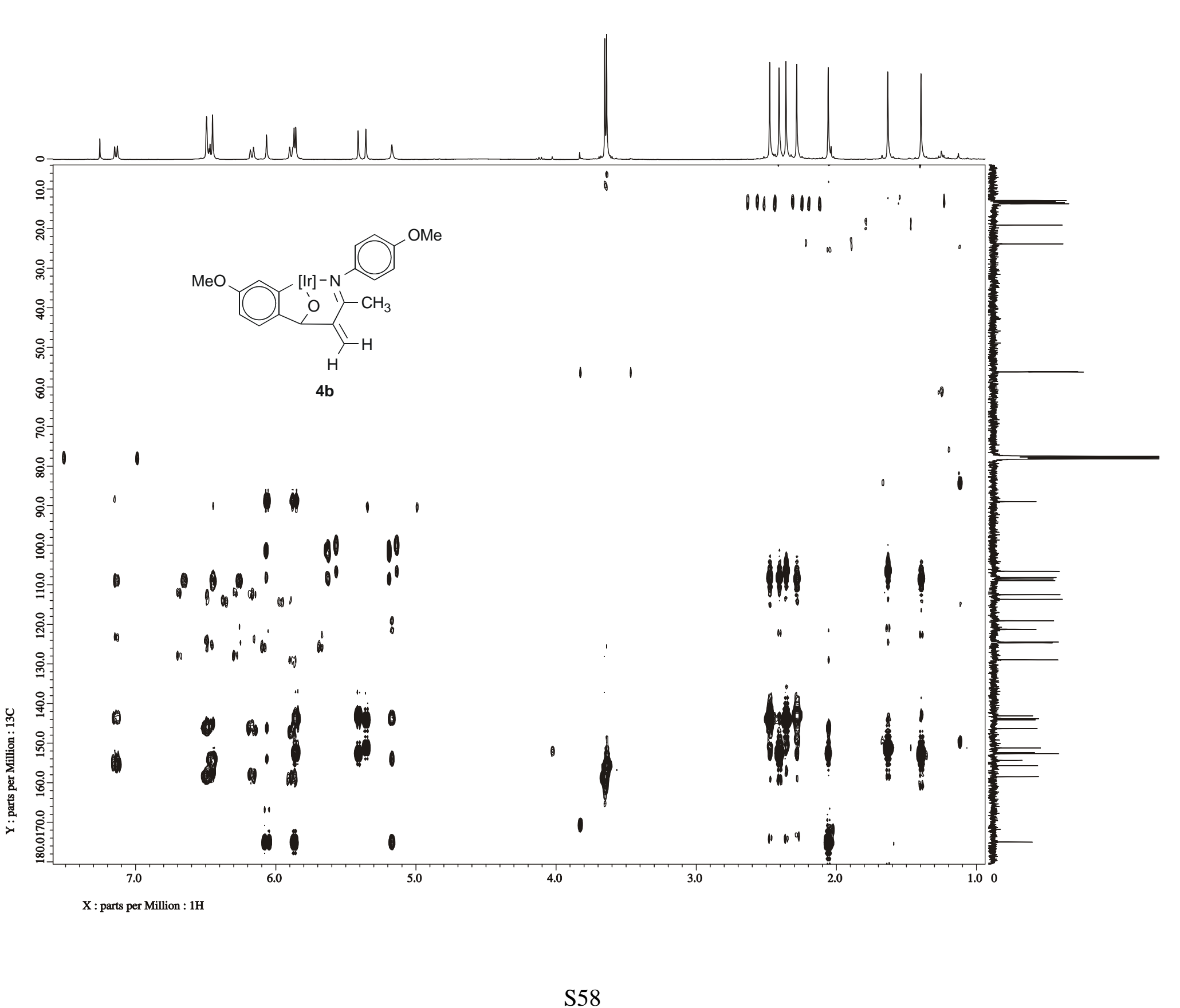

